\title{
Understanding adolescent and youth sexual and reproductive health-seeking behaviors in Ethiopia: Implications for youth friendly service programming
}

Aparna Jain

Population Council

Hussein Ismail

Population Council

Elizabeth Tobey

Population Council

Annabel Erulkar

Population Council

Follow this and additional works at: https://knowledgecommons.popcouncil.org/departments_sbsr-rh

Part of the Demography, Population, and Ecology Commons, Family, Life Course, and Society Commons, International Public Health Commons, and the Maternal and Child Health Commons How does access to this work benefit you? Let us know!

\section{Recommended Citation}

Jain, Aparna, Hussein Ismail, Elizabeth Tobey, and Annabel Erulkar. 2017. "Understanding adolescent and youth sexual and reproductive health-seeking behaviors in Ethiopia: Implications for youth friendly service programming," Research report. Washington, DC: Population Council, The Evidence Project. 
Understanding Adolescent and Youth Sexual and Reproductive Health-seeking Behaviors in Ethiopia:

Aparna Jain, Population Council

Hussein Ismail, Population Council

Elizabeth Tobey, Population Council

Annabel Erulkar, Population Council

Youth Friendly Service

Programming

$>$

0

○

20

$\Pi$

0

20

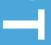

\section{SEPTEMBER 2017}

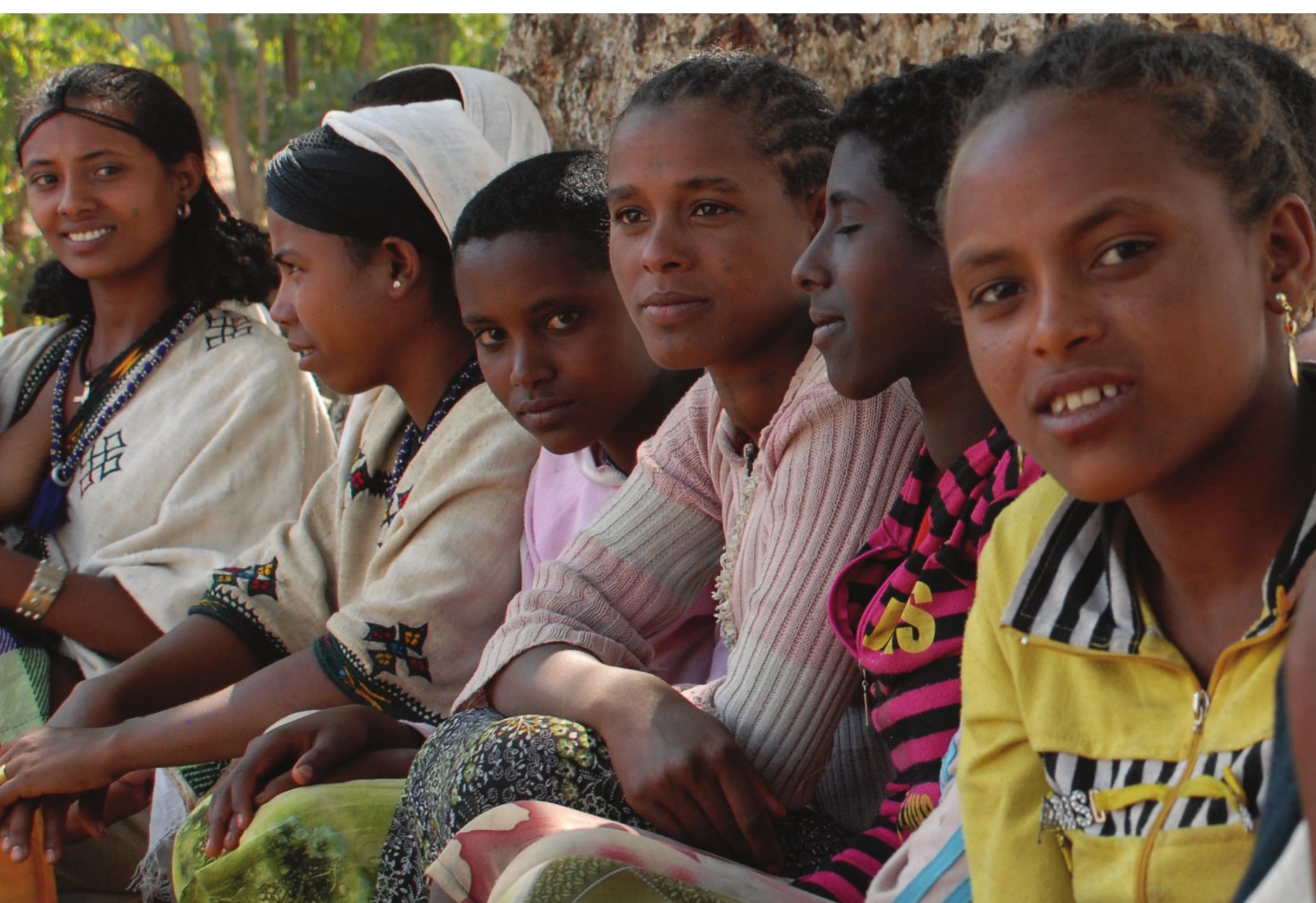


The Evidence Project is made possible by the generous support of the OSAID American people through the United States Agency for International Development (USAID) under the terms of cooperative agreement no. AIDOAA-A-13-00087. The contents of this document are the sole responsibility of the Evidence Project and Population Council and do not necessarily reflect the views of USAID or the United States Government.

\section{Evidence}

The Evidence Project uses implementation science-the strategic generation, translation, and use of evidence-to strengthen and scale up family planning and reproductive health programs to reduce unintended pregnancies worldwide. The Evidence Project is led by the Population Council in partnership with INDEPTH Network, International Planned Parenthood Federation, PATH, Population Reference Bureau, and a University Research Network.

Published in September 2017.

Suggested citation: Jain, Aparna, Hussein Ismail, Elizabeth Tobey, and Annabel Erulkar. 2017. "Understanding Adolescent and Youth Sexual and Reproductive Health-seeking Behaviors in Ethiopia: Implications for Youth Friendly Service Programming," Research Report. Washington, DC: Population Council, The Evidence Project.

Photo credit: Zeleman Productions

๑ 2017 The Population Council, Inc. 


\section{Table of Contents}

ACKNOWLEDGMENTS

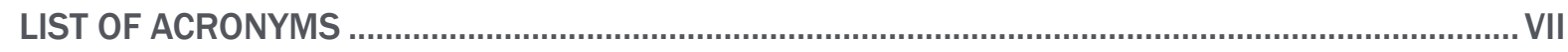

EXECUTIVE SUMMARY

INTRODUCTION .................................................................................................................... 2

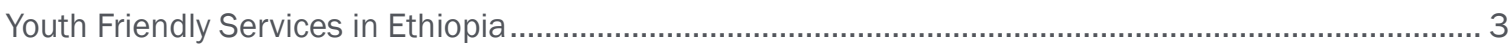

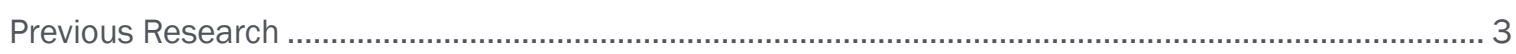

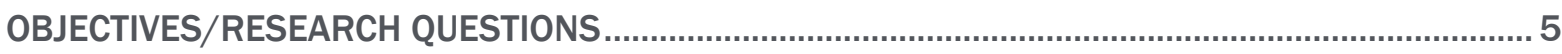

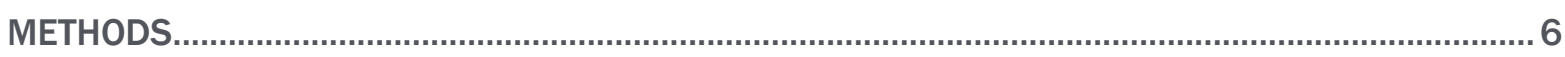

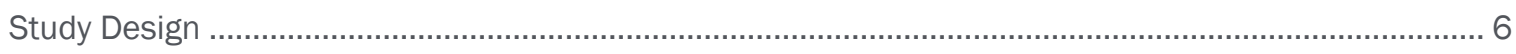

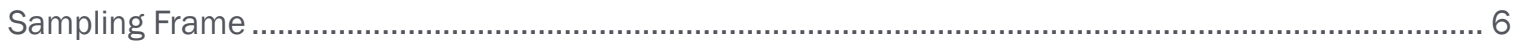

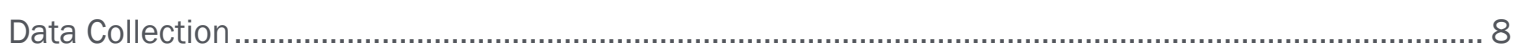

Data Quality, Management, and Analysis............................................................................................

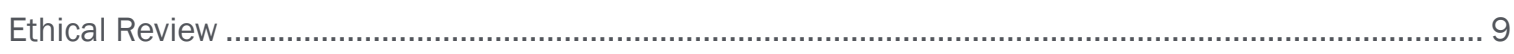

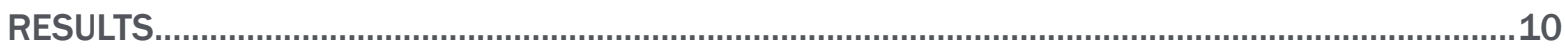

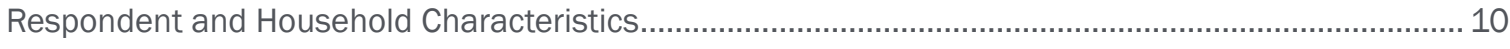

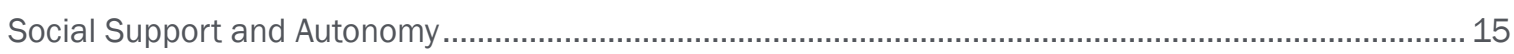

Basic Health Services and Youth Friendly Services.......................................................................... 17

Family Planning Services............................................................................................................... 24

Attitudes Around Sex, Contraception, and Gender Norms ................................................................ 34

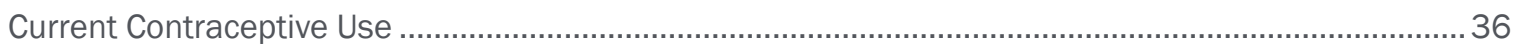

Use of YFS and Non-YFS Sites for Health Services in the Past Six Months (Females)............................ 39

Use of YFS and Non-YFS Sites for Health Services in the Past Six Months (Males)................................. 45

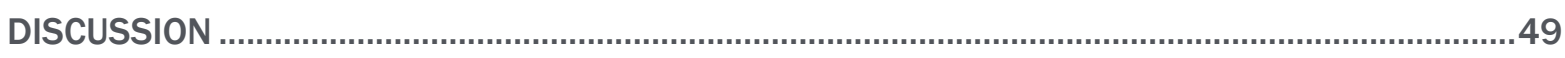

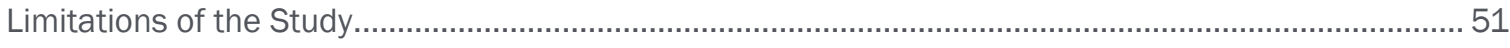

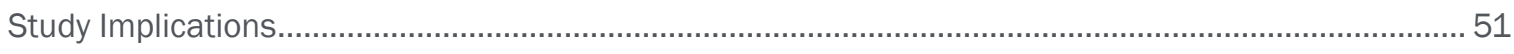

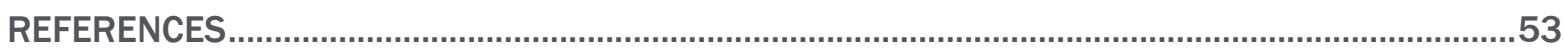

APPENDIX

\section{LIST OF FIGURES \& MAPS}

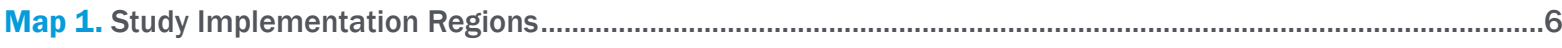

Figure 1. Percentage Distribution of Female and Male Respondents' Attitudes around Sex and Pregnancies..... 34

Figure 2. Percentage Distribution of Female and Male Respondents' Attitudes around Contraceptive Use .......... 35

Figure 3. Percentage Distribution of Female and Male Respondents' Attitudes around Contraceptive Communication 


\section{LIST OF TABLES}

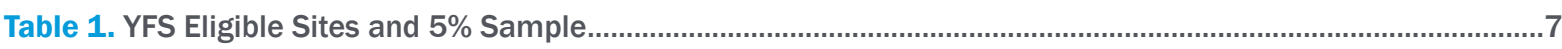

Table 2. Parameters and Assumptions for Sample Size Calculation for Young People Cross-sectional Study..........8

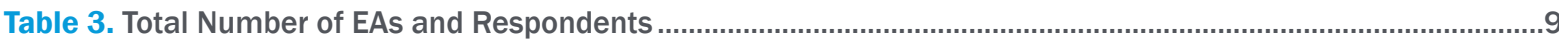

Table 4. Percentage Distribution of Female and Male Respondents by Select Background Characteristics.......... 10

Table 5. Percent of Respondents Reporting Ever Having Sex, by Age, Marital Status, and School Status............. 11

Table 6. Percent of Ever Sexually Active Respondents Reporting Age at First Sex, Current Sexual Activity, and Condom Use at Last Sex, According to Age.

Table 7. Percentage Distribution of Female and Male Respondents Reporting Household Members with Whom They Live

Table 8. Percent of Respondents Reporting Parental Marital Status by Age and Region ....................................13

Table 9. Percent of Respondents with Personal Savings by Age and Region....................................................14

Table 10. Percent of Respondents Owning a Mobile Phone by Age and Region ...................................................14

Table 11. Percent of Respondents Reporting Various Social Support Aspects by Age, Marital Status, and School Status

Table 12. Percent of Respondents Needing Permission to Leave the House or Attend Community Gatherings by Age, Marital Status, and School Status.

Table 13. Percentage Distribution of Female and Male Respondents Involved in Decision-making on Various Matters.

Table 14. Percentage Distribution of Female and Male Respondents' Basic Health Service Preferences

Table 15. Percentage Distribution of Female and Male Respondents with Knowledge of Source of Basic Health Services and Youth Friendly Services.

Table 16. Number of Female and Male Respondents with Knowledge of Services Offered at Youth Friendly Services

Table 17. Percent of Respondents Who Used Basic Health Services by Age, Region, Distance to a YFS Site ........ 21

Table 18. Percent of Respondents Who Used Youth Friendly Services by Age, Region, Distance to a YFS Site..... 22

Table 19. Percentage Distribution of YFS Users by Select Demographic Characteristics .......................................23

Table 20. Percent of Respondents with Contraceptive Knowledge by Age and Region .........................................25

Table 21. Percent of Respondents Reporting Source of Contraceptive Information by Age and Region ............... 27

Table 22. Percent of Respondents Reporting Knowledge of Source of Contraceptive Service (Females)/Condoms Services (Males)

Table 23. Percent of Respondents Reporting Preferred Location for Contraceptive Service (Females)/Condoms Services (Males)

Table 24. Percentage Distribution of Female and Male Respondents Reporting Top 3 Reasons Why Youth Selected Preferred Location for Services.

Table 25. Percent of Respondents Reporting Preferred Provider for Contraceptive (Female) or Condom (Male) Services by Age

Table 26. Percent of Respondents Reporting Preferred Contraceptive (Female)/Condom (Male) Provider Characteristics

Table 27. Percent of Sexually Active Female Respondents Reporting Contraceptive Use ......................................36

Table 28. Percent Distribution of Sexually Active Female Respondents Reporting Current Method Use ................36

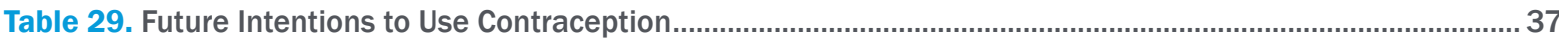

Table 30. Ever Use of Contraception Among Female Youth ............................................................................... 38 
Table 31. Percent of Sexually Active Respondents Who Have Ever Used Condoms by Select Background Characteristics..

Table 32. Reasons for Using/Not Using Condoms at Last Sex.

Table 33. Percentage Distribution of Females Who Visited a YFs/Non-YFS Site Within the Past 6 Months of the Survey, by Service Type

Table 35. Percentage Distribution of Female Users of Family Planning, Maternal Health, or Basic Health Services by Select Characteristics, According to Type of Site Visited

Table 34. Percentage Distribution of Female Users of YFS Services for Family Planning, Maternal Health, or Basic Health, Among Those Who Live Near a YFS Site

Table 36. Percentage Distribution of Females Who Visited a YFS/Non-YFS Site by Reason for Family Planning and Maternal Health Visit

Table 37. Percentage Distribution of Females Who Visited a YFS/Non-YFS Site by Outcome of Family Planning Visit.

Table 38. Percentage Distribution of Female Users of Family Planning, Maternal Health, or Basic Health Services by Mode of Transportation, According to Type of Site Visited

Table 39. Percentage Distribution of Female Users of Family Planning Maternal Health or Basic Health Services by Waiting Time, According to Type of Site Visited

Table 40. Percentage Distribution of Female Users of Family Planning, Maternal Health, or Basic Health Services by Aspects of Quality, According to Type of Site Visited

Table 41. Percentage Distribution of Female Users of Family Planning, Maternal Health, or Basic Health Services by Cost of Service Received, According to Type of Site Visited

Table 42. Percentage Distribution of Female Users of Family Planning, Maternal Health, or Basic Health Services by Affordability of Service Received, According to Type of Site Visited .

Table 43. Percentage Distribution of Males Who Visited a YFS/Non-YFS Site Within the Past 6 Months of the Survey, by Service Type

Table 44. Percentage Distribution of Male Users of YFS Services for Family Planning, Maternal Health, or Basic Health, Among Those Who Live Near a YFS Site

Table 45. Percentage Distribution of Male Users of HIV or Basic Health Services by Select Characteristics, According to Type of Site Visited.

Table 46. Percentage Distribution of Males Who Visited a YFS/Non-YFS Site by Reason for HIV Visit..... 46

Table 47. Percentage Distribution of Male Users of HIV Services or Basic Health Services Reporting Mode of Transportation, by Type of Site Visited.

Table 48. Percentage Distribution of Male Users of HIV or Basic Health Services Reporting Waiting Time by Type of Site Visited.

Table 49. Percent of Respondents Reporting Satisfaction with Services Received and Quality of Services Offered by Provider, by Type of Site Visited

Table 50. Percent of Respondents Reporting Cost of HIV and Basic Health Services Received by Type of Facility 48 


\section{Acknowledgments}

The authors wish to acknowledge the contributions of the many individuals and institutions who made this study possible. We are grateful to the USAID Mission in Ethiopia for their generous support, in particular Yoseph Woldegebriel and Joshua Karnes.

Special thanks are due to the Federal Ministry of Health (FMOH), for their continuous support in this study. We are also grateful to the Regional Health Bureaus, Zonal Health Departments and Woreda Health Offices of the study areas for their support creating an enabling environment to conduct the study. A special thanks goes out to the interviewers and supervisors for ensuring quality data were gathered.

We would like to thank several Population Council Ethiopia colleagues for their contributions to the study. Lemi Negeri provided technical leadership in the implementation of the study. Frehiwot Getachew managed the data entry and data cleaning processes. Our drivers, Mesfin Dinku, Endale Berga, and Abreham Wuzen, got the study teams to their destinations safely. Warm thanks also go to our colleagues from the Population Council DC/Evidence Project. Laura Reichenbach offered valuable support throughout the duration of the study, and reviewed and offered important inputs to the report. Karen Hardee reviewed and provided valuable feedback to the report. Julia Adams worked tirelessly with us on developing several versions of the budget. Many thanks also to Joyce Altman for copy editing the report, to Kate Gilles for her assistance with review, and to Anneka Van Scoyoc for formatting the report. We also thank Helen Tessema and Afzal Kuhnaward for assisting with the management of study budget and expenditure reports.

We are grateful to all the members of the Technical Advisory Committee (TAC), who offered helpful input at the start of the study, and to Sam Kalibala for presenting the research utilization strategy to the TAC. Thanks are also owed to our colleagues at Pathfinder/Ethiopia and Family Guidance Association of Ethiopia (FGAE) for providing information on youth friendly services.

Finally, a special thank you goes to the youth who shared their experiences and perspectives with us, without which this study and this report would not have been possible. 


\section{List of Acronyms}

\begin{tabular}{|c|c|}
\hline AYSRH & Adolescent and Youth Sexual and Reproductive Health \\
\hline EA & Enumeration Area \\
\hline EPHI & Ethiopia Public Health Institute \\
\hline FGAE & Family Guidance Association of Ethiopia \\
\hline $\mathrm{FMOH}$ & Federal Ministry of Health \\
\hline FP & Family Planning \\
\hline GBV & Gender Based Violence \\
\hline GPS & Global Positioning System \\
\hline HEW & Health Extension Worker \\
\hline HIV & Human Immunodeficiency Virus \\
\hline HSTP & Health Sector Transformation Plan \\
\hline IFHP & Integrated Family Health Program \\
\hline IPPF & International Planned Parenthood Federation \\
\hline IRB & Institutional Review Board \\
\hline IUD & Intrauterine Device \\
\hline KOICA & The Korea International Cooperation Agency \\
\hline LAM & Lactational Amenorrhea Method \\
\hline MSI & Marie Stopes International \\
\hline $\mathrm{NGO}$ & Non-governmental Organization \\
\hline PPS & Probability Proportional to Size \\
\hline PSU & Primary Sampling Unit \\
\hline RH & Reproductive Health \\
\hline SDM & Standard Days Method \\
\hline SNNP & Southern Nations, Nationalities, and People \\
\hline SRH & Sexual and Reproductive Health \\
\hline STI & Sexually Transmitted Infection \\
\hline VCT & Voluntary Testing and Counseling \\
\hline & Youth Friendly Services \\
\hline
\end{tabular}




\section{Executive Summary}

Globally, young people face distinct barriers in accessing sexual and reproductive health (SRH) services. Young people's access to these services is particularly unique in Ethiopia, where $63 \%$ of women aged $25-49$ are married by age 18 and $30 \%$ by age 15 . Furthermore, trends differ among youth in rural and urban areas. Research has shown that rural youth in Ethiopia have more lifetime sexual partners than their urban counterparts, and that contraceptive use is 10 times lower among rural young people than urban young people (Seifu, Fantahun, \& Worki 2006). Acknowledging the need for targeted health services for adolescents and youth, the Ethiopian Government has scaled-up and institutionalized youth friendly services (YFS) through intensive capacity building at all levels of the health system (Hainsworth et al. 2014). However, since the introduction of YFS in Ethiopia, few studies have examined the utilization of adolescent and youth SRH services in urban areas, and even fewer have focused on utilization in rural areas.

In collaboration with USAID/Ethiopia and the Ethiopian Federal Ministry of Health $(\mathrm{FMOH})$, the "Understanding Adolescent and Youth Sexual and Reproductive Health-Seeking Behaviors in Ethiopia" study aimed to generate evidence on current use and perspectives of YFS and to inform the FMOH in its future SRH programming for young people. A cross-sectional quantitative survey was implemented between January and July 2016, with 3,611 females and males aged 12-24 years living in rural and periurban areas of Amhara, Oromia, Tigray, SNNP, and Benishangul-Gumuz regions. Survey respondents were randomly selected from a list of households within either 5 or $10 \mathrm{~km}$ of selected health facilities with YFS or within the same distance from a health facility without YFS as a comparison. Informed consent was received from all respondents before continuing on with the survey. The survey questions covered a range of topics including (but not limited to) respondent and household characteristics, use of basic health services, contraceptive use and sexual activity, awareness of YFS, and use of YFS. Bivariate analysis was conducted by sex, region, age, marital status, and school status.

Results from this study show that young people surveyed were satisfied overall with the health services they received, regardless of whether it was basic health services or YFS. Only a small proportion of youth had knowledge of YFS, and an even smaller proportion reported using YFS prior to the survey. However, among respondents who reported using contraception, many may have been using YFS without knowing it. Lastly, respondents reported low levels of social autonomy and required permission to leave the house from either a parent or spouse. This may be a barrier for young people in accessing health services, and especially SRH services.

With high levels of satisfaction services from both YFS sites and non-YFS sites, policymakers need to consider how to best use their resources to improve access to and quality of youth-centered health services. Since married youth are the main users of youth-centered SRH services, programs should target married youth rather than youth more broadly. Furthermore, due to the distance some youth travel to reach YFS and non-YFS, programs should bring SRH services to youth in their communities, generate greater awareness and demand for these youth-centered services, and change community norms around youth SRH services in rural areas. 


\section{Introduction}

The global community now recognizes that young people have unique challenges when accessing sexual and reproductive health services. As young people transition into adulthood, their sexual and reproductive health needs change and it is important to reach this population with appropriate and relevant information and services and address their developmental needs. Reviews and commentaries that cull the literature to assess interventions of youth friendly services that hold promise in achieving reproductive health outcomes have been documented more recently in addition to common barriers encountered by young people in accessing sexual and reproductive health (SRH) services (Brittain et al. 2015; Chandra-Mouli et al. 2015; High-Impact Practices in Family Planning 2015).

The Ethiopian Government has made great strides in supporting services for young people. Over the past decade, the government has developed several policies and guidelines to support the implementation of YFS. In 2006, the Federal Ministry of Health (FMOH) released the National Adolescent and Youth Reproductive Health Strategy (AYRHS 2006-2015) that lays out the vision and objectives for increasing access and use of quality reproductive health information and services. In this document, it is mentioned that "youth friendly services is not primarily about setting up separate dedicated services, although the style of some facilities may change. The greatest benefit comes from improving generic health services in local communities and by improving the competencies of health care providers to deal effectively with adolescents" (page 35). Characteristics of youth friendly services as identified in this document are available in Box 1 in the Appendix.

Building on this strategy, the FMOH developed guidelines, tools, and training curricula to assist in the implementation of YFS. In 2006, the FMOH developed a standard and guidelines document called the Standards on Youth Friendly Reproductive Health Services: Service Delivery Guideline and Minimum Service Delivery Package on YFRH Services. The intended package of youth friendly services to be available include:

- Information and counseling on reproductive and sexual health issues, and sexuality

- Promotion of healthy sexual behaviors through various methods, including peer education

- Family Planning information, counseling, and methods, including emergency contraceptive methods.

- Condom promotion and provision

- Testing services: Pregnancy, HCT

- Management of sexually transmitted infections

- Antenatal care, delivery services, postnatal care, and prevention of mother to child transmission (PMTCT)

- Abortion and post-abortion care

- Appropriate referral linkage between facilities at different levels

The guidelines further articulate the service delivery points in order to reach both urban and rural youth with a range of SRH services including:

- Hospitals: Public, Private, Faith-Based Organizations, and Nongovernmental Organizations.

- Health Centers: Public, Private, Faith-Based Organizations, and Nongovernmental Organizations.

- Clinics/Health Stations: Public, Private, Faith-Based Organizations, and Nongovernmental Organizations, Universities, Schools.

- Health posts: Public. 
- Dispensary (Pharmacy, Rural Drug Vendors): Public, Private, Faith-Based Organizations and Nongovernmental Organizations, Universities, Schools.

- Other/Community Outlets: Youth centers, the in- and out-of-school youth anti-AIDS and Reproductive Health Clubs, Health Extension Workers (HEWs), and community and school outreach services.

In 2008, the FMOH developed a training curriculum called the National Comprehensive Reproductive Health Services for Adolescents and Youth. In 2010, the FMOH developed planning, implementation, and monitoring tools for young people's reproductive health service standards in order to identify and fill implementation gaps related to YFS at health facilities.

The Ethiopian Government, along with several international and local NGOs, has been supporting activities to increase access to SRH services for young people. The government of Ethiopia pursued scale-up and institutionalization of YFS through intensive capacity building at all levels of the health system over the past eight years (Hainsworth et al. 2014). Youth friendly services were offered through multiple servicedelivery channels, including community-based distribution, and quarterly review meetings were held among district and regional health authorities and health providers to review monitoring data and address quality of care issues (Hainsworth et al. 2014).

\section{YOUTH FRIENDLY SERVICES IN ETHIOPIA}

Under Pathfinder's Integrated Family Health Program (IFHP), a USAID-funded project, 20 YFS sites in four regions in 2005 were scaled up to 163 sites in 6 regions in 2012 (Amhara, Benishangul-Gumuz, Oromia, SNNP, Somali, and Tigray), and transition to government implementation occurred from 20122014 (Hainsworth et al. 2014). IFHP's program activities are aimed at reducing young people's barriers to health services by addressing barriers at the structural, social, and individual levels (Pathfinder 2012). A comprehensive package of services is offered to young people at facility-based YFS centers, ranging from pregnancy-related care to HIV counseling, testing, and treatment to contraceptive counseling and method provision (Pathfinder 2012). In addition, IFHP trained peer health educators to create awareness of and generate demand for the facility-based YFS services in their communities (Pathfinder 2012).

In addition to the IFHP YFS approach, the Family Guidance Association of Ethiopia (FGAE), an IPPFaffiliate, has also been working on young people's health services for some time. FGAE introduced youth friendly SRH services in 1989. The overall aim of FGAE is to bring comprehensive and high-quality SRH information and youth friendly services to young people, and its YFS delivery approach has been expanded to over 350 multipurpose youth centers across the country. In rural areas, FGAE primarily works through outreach programs linked to youth centers. Several additional organizations work on adolescent and youth sexual and reproductive health (AYSRH) services, including Marie Stopes International (MSI).

In collaboration with USAID/Ethiopia, the rationale for this study was to generate evidence that will inform the FMOH in its future SRH programming for young people as well as in the development of the next Health Sector Transform Plan (HSTP). This study will also be useful for both the FMOH and USAID/ Ethiopia by providing information related to the current status, best practices, and future opportunities for improving reproductive health services for young people in Ethiopia.

\section{PREVIOUS RESEARCH}

Youth access to SRH services is particularly unique in Ethiopia, where $41 \%$ of women aged $20-24$ were married by age 18, while $16 \%$ were married by age 15 . Early age at marriage coupled with high rates of youth childbearing ( $71 \%$ of women aged 15-24 had a live birth or were pregnant according to the 2011 Ethiopia DHS) make Ethiopian young people particularly vulnerable to maternal mortality and morbidity. In addition, despite the rise in use of modern contraceptive methods among 15-24 year olds from 5\% in 2000 to $27 \%$ in 2011, unmet need is greatest in Ethiopia among 15-19 year olds at 32\% in 2011. 
Furthermore, a quarter of pregnant 15-24 year olds feel that their pregnancy was mistimed or unwanted (Central Statistical Agency and ICF International 2012).

With $81 \%$ of Ethiopia's population residing in rural areas, rural-urban inequities in access to SRH services are critical for youth. Rural youth (both boys and girls) are more likely to be sexually active but less likely to use contraception compared to their urban counterparts (Seifu et al. 2006), which is driven primarily by high rates of early marriage. Compared to urban girls, rural girls are likely to get married at younger ages (median age: 16.6 rural vs 19.3 urban), have greater unmet need for family planning (29\% rural vs $15 \%$ urban); and higher fertility rates (15-19 years old: 99 per 1,000 rural vs 27 per 1,000 urban; 20-24 years old: 236 per 1,000 rural vs 123 per 1,000 urban) .

Very few studies have examined the utilization of AYSRH services in urban and rural areas. One study in two slum areas in Addis Ababa found that boys accessed FP/RH services two to three times more than girls, and that older boys and girls were more likely to utilize programs (Erulkar et al. 2006). Another study in Amhara region demonstrated that $\mathrm{FP} / \mathrm{RH}$ service utilization among young people was significantly associated with educational status and with discussions about FP/RH issues with family or relatives, peer groups, sexual partners, or teachers (Feleke et al. 2013). Finally, a community-based cross-sectional study in rural Amhara region found that 13\% of 10-19 year olds used RH services, including FP, STI, and VCT services (Abajobir \& Seme 2014).

A study of over 10,000 12-24 year olds in urban and rural areas of seven regions in Ethiopia demonstrated that male and female respondents both considered friendly staff and providers as the most important characteristic of youth friendly services (YFS) followed by low-cost/free services and close proximity to place of residence (Erulkar et al. 2010). This study also showed that distance to a health center, private clinic, or hospital could pose as a major barrier to accessing services, especially among rural respondents who took on average over two hours to travel to and from these facilities. Furthermore, findings from this study demonstrated that premarital sex is low, girls and young people experience sex for the first time within marriage, and youth centers tend to reach boys and young men.

Several cross-sectional research studies have been conducted among in-school young people in Ethiopia. Research has shown that low levels of care-seeking behaviors for family planning/reproductive health (FP/RH) issues exist among high school students in Addis Ababa (Cherie \& Berhane 2012). Reasons for not seeking FP/RH services included negative perceptions about the availability of YFS, unfriendly and untrained health professionals, and a lack of access to affordable and acceptable services (Cherie \& Berhane 2012). Abajobir and Seme (2014) reported that parental disapproval, lack of basic FP/RH information, and pressure from partners deters adolescents from accessing RH services. Students aged 10-24 reported that they preferred YFS that had special service hours dedicated to adolescents and were discounted or free (Berhane, Berhane, \& Fantahun 2005). 


\section{Objectives/Research Questions}

The objectives of the overall study were:

1. To assess awareness and perceptions of available SRH services among young people aged 12-24 years old - females and males, unmarried and married, in school and out of school.

2. To explore service utilization patterns and behaviors, and preferences and experiences obtaining SRH services from different sources; and to document reasons for nonuse of SRH services and potential solutions among young people aged $12-24$ years old. 


\section{Methods}

\section{STUDY DESIGN}

A cross-sectional quantitative household survey was implemented among youth ages 12-24 years living in rural or peri-urban areas to understand their perceptions of existing SRH services and to explore service utilization patterns and behaviors. The study was implemented in Amhara, Benishangul-Gumuz, Oromia, SNNP, and Tigray regions (see Map 1).

\section{SAMPLING FRAME}

\section{Youth Friendly Service Sites}

The first activity in determining the sampling strategy was to identify the number of YFS sites in each region. Study team members traveled to the regional health bureaus of Amhara, Oromia, Tigray, SNNP, Somali, and Benishangul-Gumuz to gather the number of supported YFS activities by organization, funder, and location. As of 2015, there were a total of 323 YFS sites. YFS sites identified include: health centers, hospitals, universities, and youth centers.

Previous research has shown that among rural residents, access to health service is difficult

MAP 1. STUDY IMPLEMENTATION REGIONS

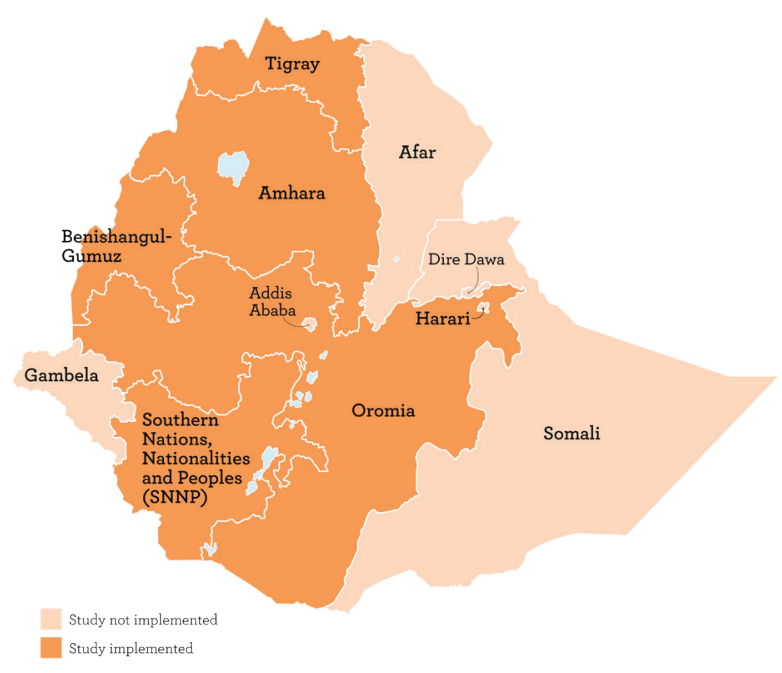
because of the distance from a facility. The study team therefore decided to select YFS sites in each region and draw two concentric rings around them: 1) with a 5 kilometer $(\mathrm{km})$ radius and 2) with a $15 \mathrm{~km}$ radius. Within each concentric ring, enumeration areas (EAs) were identified and randomly selected, household listings were completed in each EA, and youth were randomly selected from eligible households.

Given that the intention was to study rural and peri-urban youth service-use behaviors, 21 YFS sites were excluded because they were located in urban areas -8 sites were embedded in universities, 4 sites were in urban hospitals, 3 sites were new or nonfunctional (i.e., no trained provider was working at the site), and 6 sites were located in cities/towns. In addition, 55 UNFPA/UNICEF sites were also excluded as they were only available in Tigray region. Somali region was dropped from the study because the YFS sites were located in the capital. The total number of YFS sites was 247 in 5 regions, which also made up the sampling frame for this study.

Approximately 5\% of all functional/eligible YFS sites were selected for inclusion in this study. The number of YFS was determined by probability proportional to size (PPS) and selected using systematic random sampling.

One facility per region was also selected for comparison purposes. These comparison facilities did not receive any support or trainings in YFS. When possible, the comparison facilities were selected from within the same zone of the selected YFS site.

Table 1 shows the eligible YFS sites by region, funding agency, and number of selected sites for the study. YFS sites funded by USAID/KOICA are under Pathfinder's Integrated Family Health Program (IFHP) portfolio. A total of 14 YFS sites were selected across the five regions, varying from 1 to 4 . One comparison facility was also selected in each region. 
TABLE 1. YFS ELIGIBLE SITES AND $5 \%$ SAMPLE

\begin{tabular}{|c|c|c|c|c|c|c|c|c|}
\hline \multirow[b]{2}{*}{ Region } & \multicolumn{3}{|c|}{ No. of eligible of YFS by agency } & \multicolumn{3}{|c|}{$5 \%$ sample PPS } & \multirow[b]{2}{*}{$\begin{array}{c}\text { Comparison } \\
\text { facility }\end{array}$} & \multirow[b]{2}{*}{ Tota } \\
\hline & $\begin{array}{l}\text { USAID/ } \\
\text { KOICA }\end{array}$ & FGAE & Total & $\begin{array}{l}\text { USAID/ } \\
\text { KOICA }\end{array}$ & FGAE & Total & & \\
\hline Tigray & 54 & 1 & 55 & 2 & 1 & 3 & 1 & 4 \\
\hline Oromia & 58 & 9 & 67 & 3 & 1 & 4 & 1 & 5 \\
\hline SNNP & 57 & 3 & 60 & 2 & 1 & 3 & 1 & 4 \\
\hline Amhara & 54 & 5 & 59 & 2 & 1 & 3 & 1 & 4 \\
\hline $\begin{array}{l}\text { Benishangul- } \\
\text { Gumuz }\end{array}$ & 6 & - & 6 & 1 & - & 1 & 1 & 2 \\
\hline Total & 229 & 18 & 247 & 11 & 4 & 14 & 5 & 19 \\
\hline
\end{tabular}

In several regions, randomly selected YFS sites were replaced if they were located in large towns and not rural or peri-urban areas after field visits had been made to them by the study team. GPS coordinates of the selected YFS sites and comparison sites were taken during the site visits. A GPS specialist and an enumeration specialist worked on identifying enumeration areas that fell within $5 \mathrm{~km}$ of YFS sites, between 5 to $15 \mathrm{~km}$ of YFS sites, and within $5 \mathrm{~km}$ of comparison facilities. Maps were drawn that showed the enumeration areas that fell within the $5 \mathrm{~km}$ and that fell within 5-15 km from YFS and comparison centers. From these maps, it became clear, especially in Tigray, that there was considerable overlap of enumeration areas between facilities (either between two YFS sites or one YFS site and a comparison site). Based on these maps and the need to reduce overlap (which could not be completely eliminated), the study team decided to reduce the farthest distance from $15 \mathrm{~km}$ to $10 \mathrm{~km}$.

\section{Enumeration Areas and Households}

For the YFS sites, this study used a stratified, two-stage cluster design where EAs are the primary sampling unit (PSU) in the first stage. The EAs were stratified by distance from the YFS site, $<5 \mathrm{~km}$ or $5 \mathrm{~km}$ to $<10 \mathrm{~km}$, and three EAs were selected from each strata. Administratively, regions in Ethiopia are divided into zones; zones are divided into administrative units called woredas. Each woreda is further subdivided into the lowest administrative unit called kebele. During the 2007 census, each kebele was subdivided into census enumeration areas (EAs). EAs consist of roughly 150-200 households in rural areas.

Households comprised the second sampling stage. Using a list of EAs by kebele, a complete list of all household members was completed within each selected EA to identify households that contained eligible respondents. Households containing eligible respondents were then selected randomly, and one eligible respondent per household was selected using a KISH grid (Kish 1949). No further stratification was done-i.e., no stratification was done by age or by gender.

For the comparison sites, a two-stage cluster design was used to select eligible respondents living within $5 \mathrm{~km}$ of a comparison facility. Again, the first stage was the EAs, and households comprised the second stage. Unlike the YFS sites where EAs were selected within $5 \mathrm{~km}$ and more than $5 \mathrm{~km}$ away from the YFS site, in comparison facilities EAs were only selected within $5 \mathrm{~km}$ of the facility and 4 EAs were selected per comparison facility. A complete listing of all household members was conducted to identify households that contained eligible respondents. Households containing eligible respondents were selected randomly.

\section{Sample Size}

The sample size was calculated based on service utilization indicator estimates found in a literature review of youth access to health services in Ethiopia. We used an estimate of approximately $20 \%$ of young people who had ever used RH services, including family planning, sexually transmitted infection (STI) treatment and information, found in Abajobir and Seme (2014) to determine the minimum sample size for this 
study. We assumed that this figure applies to youth located within $5 \mathrm{~km}$ of the YFS site. To account for the homogeneity/correlation of respondents residing within the same cluster, the sample size was adjusted for the design effect. Typically, the design effect is held at 1.5. In addition, a nonresponse rate of $10 \%$ was applied to the final sample size calculation. We used the sampsi command for two independent populations in Stata.13 to determine the sample size presented in Table 2. The following is the formula for sample size of two independent populations:

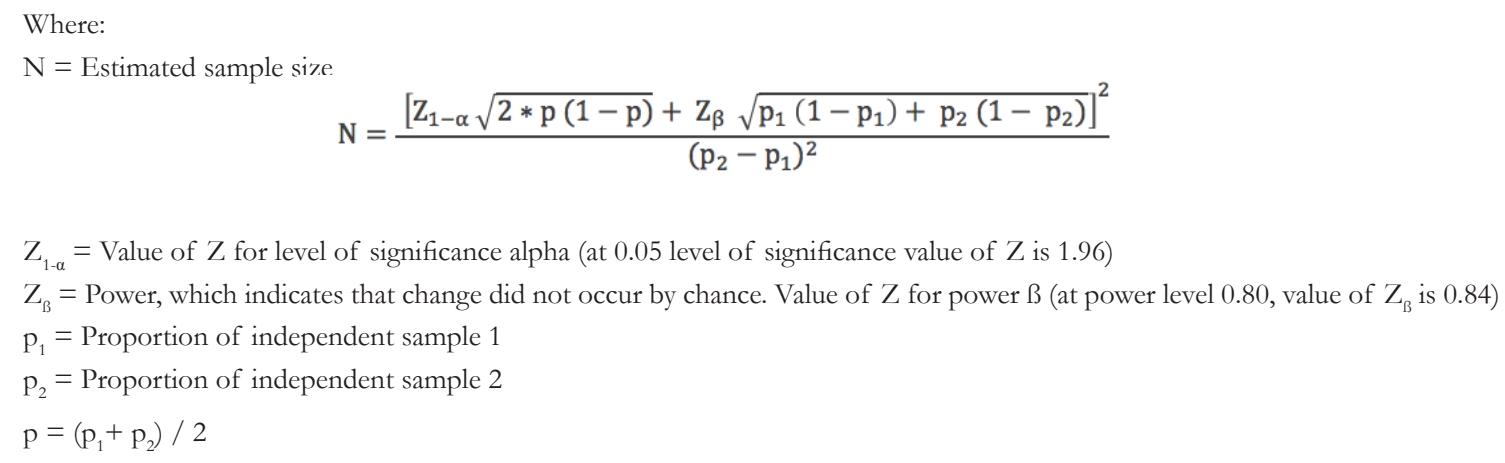

Table 2 shows the sample size calculations for two populations: youth residing within $5 \mathrm{~km}$ of a YFS site and youth residing more than $5 \mathrm{~km}$ away from a YFS site. Note that this sample size calculation does not include the respondents interviewed in the comparison (non-YFS) sites.

\section{TABLE 2. PARAMETERS AND ASSUMPTIONS FOR SAMPLE SIZE CALCULATION FOR YOUNG PEOPLE CROSS-SECTIONAL STUDY}

\begin{tabular}{ll}
\hline Population & Young people \\
Parameters & $\%$ of young people (10-19 years old) who have ever used reproductive health services \\
$5 \mathrm{~km}$ from YFS & $20 \%$ \\
$10 \mathrm{~km}$ from YFS & $14.4 \%$ \\
Number of respondents & $896<5 \mathrm{~km}$ distance \\
& $8965-10 \mathrm{~km}$ distance \\
Design effect & 1.5 \\
Non-response & $10 \%$ \\
Total calculated sample & $1,438<5 \mathrm{~km}$ distance \\
& $1,4385-10 \mathrm{~km}$ distance \\
\hline
\end{tabular}

We selected a fixed number of respondents per EA (Ahmed 2009) at 37. Table 3 outlines the number of YFS, EAs, projected respondents interviewed by stratification of $<5 \mathrm{~km}$ from a YFS, 5-10 km from a YFS, and $<5 \mathrm{~km}$ from a comparison facility, and actual number of respondents interviewed. These data are presented by region.

\section{DATA COLLECTION}

\section{Training}

In each region, the household listing was conducted first. A one-day training took place in each region (Amhara and Benishangul-Gumuz were combined) to review the purpose and implementation method of the household listing. Roughly 19 supervisors and 109 data collectors were hired and participated in the training.

Two kebele leaders served as guides to assist in identifying all households in the kebele. The kebele guides, 
TABLE 3. TOTAL NUMBER OF EAS AND RESPONDENTS

\begin{tabular}{|c|c|c|c|c|c|c|}
\hline & Tigray & SNNP & Oromia & Amhara & $\begin{array}{c}\text { Benishangul- } \\
\text { Gumuz }\end{array}$ & Total \\
\hline YFS site & 3 & 3 & 4 & 3 & 1 & 14 \\
\hline EAs $<5 \mathrm{~km}$ & 3 & 3 & 3 & 3 & 3 & 15 \\
\hline EAs 5-10 km & 3 & 3 & 3 & 3 & 3 & 15 \\
\hline Comparison facilities & 1 & 1 & 1 & 1 & 1 & 5 \\
\hline EAs $<5 \mathrm{~km}$ & 4 & 4 & 4 & 4 & 4 & 20 \\
\hline Total EAs & 22 & 22 & 28 & 22 & 10 & 104 \\
\hline \multicolumn{7}{|l|}{ Projected number of respondents } \\
\hline Number of respondents per EA & 37 & 37 & 37 & 37 & 37 & 185 \\
\hline Total number of respondents & 814 & 814 & 1,036 & 814 & 370 & 3,848 \\
\hline \multicolumn{7}{|l|}{ Actual number of respondents } \\
\hline$<5 \mathrm{~km}$ from $\mathrm{YFS}$ & 281 & 304 & 393 & 302 & 111 & 1,391 \\
\hline $5-10 \mathrm{~km}$ from YFS & 350 & 314 & 413 & 365 & 73 & 1,515 \\
\hline$<5 \mathrm{~km}$ from non-YFS & 148 & 136 & 130 & 145 & 146 & 705 \\
\hline Total number of respondents & 779 & 754 & 936 & 812 & 330 & 3,611 \\
\hline
\end{tabular}

supervisors, and data collectors toured the boundary of the EA for delineation first before beginning collecting data for the listing. It took approximately 8 to 12 days to complete household listings in each region.

In all regions, a nine-day training took place with supervisors and data collectors that was led by the study team. During the trainings, data collectors were given an orientation about the study objectives and purpose, the importance of obtaining informed consent, and the proper procedures for obtaining informed consent outline in the protocol. Each question was reviewed during the training and mock interviews were conducted allowing data collectors to practice implementing the informed consent procedures and the survey questions. Male and female data collectors were hired. Male data collectors interviewed male respondents, and female data collectors interviewed female respondents. Data collection took approximately three to four weeks in each region.

\section{DATA QUALITY, MANAGEMENT, AND ANALYSIS}

After each day of data collection, supervisors reviewed completed questionnaires for accuracy and completeness and provided data collectors with feedback related to, for example, incorrect skip patterns or illegible/incorrect documentation. The data were entered at the Population Council office in Ethiopia by experienced data entry clerks into EpiData version 3.1. All data are stored in locked cabinets in a locked room at the Population Council office in Ethiopia.

Entered data were transformed into Stata software for cleaning and analysis. Bivariate analysis was conducted by sex, region, age, marital status, and school status and are presented in this report.

\section{ETHICAL REVIEW}

This protocol received Institutional Review Board (IRB) approval from the Population Council on July 28, 2015. In-country ethical approval was sought from the Ethiopia Public Health Institute (EPHI) and was received on November 2, 2015. The five Regional Health Bureaus where the study took place also reviewed and approved the protocol. In addition, before the household listing, support letters were obtained from the regional health bureau and submitted to the Zonal Health Offices. The Zonal Health Offices in turn provided support letters that were submitted to the woreda that in turn provided support letters that were submitted to the Kebele Chairperson (Leader). 


\section{Results}

\section{RESPONDENT AND HOUSEHOLD CHARACTERISTICS}

\section{Respondent Characteristics}

Table 4 presents characteristics of respondents interviewed in this study. A total of 1,823 females and 1,788 were interviewed. An even distribution of age groups were interviewed for both the female and male samples. Slightly more than half of female youth were between the ages of 18 and 24 years old (52\%). Most females interviewed were single (67\%) and most had attended primary school (62\%). About half of the females interviewed were Orthodox Christian (54\%). A close to even proportion of female youth were interviewed across the five regions. Among male youth, a little less than half were 18-24 years old (48\%)

\section{TABLE 4. PERCENTAGE DISTRIBUTION OF FEMALE AND MALE RESPONDENTS BY SELECT BACKGROUND CHARACTERISTICS ${ }^{\dagger}$}

\begin{tabular}{|c|c|c|}
\hline & $\begin{array}{c}\text { Females } \\
(n=1,823)\end{array}$ & $\begin{array}{c}\text { Males } \\
(n=1,788)\end{array}$ \\
\hline \multicolumn{3}{|l|}{ Age } \\
\hline $12-14$ & 27.1 & 30.4 \\
\hline $15-17$ & 21.2 & 21.1 \\
\hline $18-24$ & 51.7 & 48.4 \\
\hline \multicolumn{3}{|l|}{ Region } \\
\hline Tigray & 22.2 & 21.0 \\
\hline Amhara & 22.4 & 22.5 \\
\hline Oromia & 24.3 & 27.6 \\
\hline Benishangul-Gumuz & 10.4 & 7.9 \\
\hline SNNP & 20.7 & 21.1 \\
\hline \multicolumn{3}{|l|}{ Marital Status } \\
\hline Single & 67.3 & 90.6 \\
\hline In union/married & 28.4 & 8.4 \\
\hline Widowed/divorced/separated & 4.4 & 0.9 \\
\hline \multicolumn{3}{|l|}{ Educational Attainment } \\
\hline Never attended school & 15.4 & 7.5 \\
\hline Primary & 61.8 & 72.2 \\
\hline Secondary & 18.8 & 18.0 \\
\hline Technical/Vocational & 2.8 & 1.5 \\
\hline Higher & 1.1 & 0.6 \\
\hline \multicolumn{3}{|l|}{ School Status } \\
\hline In school & 38.0 & 41.4 \\
\hline Out of school/never attended & 62.0 & 58.6 \\
\hline \multicolumn{3}{|l|}{ Religion } \\
\hline Orthodox Christian & 53.6 & 54.2 \\
\hline Muslim & 35.7 & 36.0 \\
\hline Protestant & 9.2 & 9.1 \\
\hline Catholic & 0.3 & 0.4 \\
\hline Other & 1.2 & 0.3 \\
\hline
\end{tabular}
and the majority interviewed were single (91\%). Close to 3 in 4 males had attended primary school $(72 \%)$ and $41 \%$ were in school at the time of the survey. A little more than half were Orthodox Christian (54\%).

Table 5 and Table $\mathbf{6}$ show respondents' reported sexual activity. Only respondents who were over age 14 at the time of the interview were asked questions about their sexual activity. Among 15-24 year olds, $48 \%$ of female youth and $34 \%$ of male youth reported to have ever had sexual intercourse. When disaggregated by age, 18-24 year old female and male youth were significantly more likely to have ever had sex than 15-17 year old youth. Among single female and male youths, $5 \%$ of females and $24 \%$ of males reported that they have had sex. A significantly greater proportion of female (66\%) and male (45\%) youth who are currently not in school also reported that they have had sex.

Among females who have ever had sex, the majority were married at $82 \%$ (data not shown). Among males who have ever had sex, $62 \%$ were never married and $35 \%$ were married. This suggests that sexually activity among females tends to be within marriage while for males it begins before marriage.

Among respondents who reported having sexual intercourse, the majority of $15-17$ and 18-24 year old females

tColumn percentages may not add to $100 \%$ due to missing values. 
TABLE 5. PERCENT OF RESPONDENTS REPORTING EVER HAVING SEX, BY AGE, MARITAL STATUS, AND SCHOOL STATUS ${ }^{\dagger}$

\begin{tabular}{lcc:cc} 
& \multicolumn{2}{c}{ Females } & \multicolumn{2}{c}{ Males } \\
\cline { 2 - 5 } & $\%$ & Total $\mathrm{n}$ & $\%$ & Total $\mathrm{n}$ \\
\hline Age & $* *$ & & $* *$ & \\
15-17 & 9.3 & 386 & 9.0 & 378 \\
18-24 & 63.1 & 943 & 44.7 & 866 \\
Marital Status & $* *$ & & $* *$ & \\
$\quad$ Single & 5.4 & 734 & 24.1 & 1,078 \\
In union/married & 99.6 & 516 & 98.0 & 149 \\
$\quad$ Widowed/divorced/separated & 97.5 & 79 & 87.5 & 16 \\
School Status & $* *$ & & $* *$ & \\
$\quad$ In school & 9.4 & 438 & 17.5 & 491 \\
$\quad$ Out of school/never attended & 66.2 & 891 & 44.5 & 753 \\
Total & 47.5 & 1,329 & 33.8 & 1,244 \\
\hline
\end{tabular}

${ }^{\dagger} 12-14$ year olds are excluded from this analysis.

${ }^{*} p<0.05 ; * \star p<0.01$

TABLE 6. PERCENT OF EVER SEXUALLY ACTIVE RESPONDENTS REPORTING AGE AT FIRST SEX, CURRENT SEXUAL ACTIVITY, AND CONDOM USE AT LAST SEX, ACCORDING TO AGE ${ }^{\dagger}$

\begin{tabular}{|c|c|c|c|c|}
\hline & \multicolumn{2}{|c|}{ Ever sexually active females } & \multicolumn{2}{|c|}{ Ever sexually active males } \\
\hline & $\begin{array}{l}15-17 \\
(n=36)\end{array}$ & $\begin{array}{c}18-24 \\
(n=594)\end{array}$ & $\begin{array}{l}15-17 \\
(n=34)\end{array}$ & $\begin{array}{l}18-24 \\
(n=387)\end{array}$ \\
\hline Age at first sex & ** & & $* *$ & \\
\hline$<15$ years & 27.8 & 9.4 & 32.4 & 3.9 \\
\hline $15-17$ & 72.2 & 49.9 & 67.7 & 39.8 \\
\hline $18-24$ & - & 40.5 & - & 56.1 \\
\hline Total & 100.0 & 100.0 & 100.0 & 100.0 \\
\hline $\begin{array}{l}\text { Current sexual activity } \\
\text { (reported sex in past month) }\end{array}$ & 66.7 & 69.6 & 32.4 & 42.8 \\
\hline Used condom in last sex & 2.8 & 2.2 & 55.9 & 33.9 \\
\hline
\end{tabular}

${ }^{\dagger 12-14}$ year olds are excluded from this analysis.

$\star p<0.05 ; * \star p<0.01$

reported that age at first sex was between 15 and 17 years of age at $72 \%$ and $50 \%$, respectively (Table 6). Among males, however, over half of 18-24 year olds reported that age at first sex occurred between 18 and 24 years of age $(56 \%)$. Respondents were also asked if they had had sexual intercourse in the past month, for an indicator of current sexual activity. More female youth than male youth are currently sexually active regardless of age. This is primarily due to the higher proportion of marriage among females. When asked if they used a condom at last sex, many more males reported that they did, compared to females. This may be due to the fact that females have sex in marriage and may be less likely to use condoms in marriage. Older males $(34 \%)$ were significantly less likely to use condoms at last sex compared to younger males $(56 \%)$. 


\section{Household Members}

In Table 7, respondents reported the household members they are currently living with. The majority of females lived with their mothers $(62 \%)$ or fathers $(47 \%)$. In contrast, more males lived with their mothers or fathers at $83 \%$ and $65 \%$, respectively. Twenty-five percent of females interviewed lived with husbands, but only $8 \%$ of males lived with wives. Twenty-two percent of females lived with their own children, while only $4 \%$ of males lived with their own children.

TABLE 7. PERCENTAGE DISTRIBUTION

OF FEMALE AND MALE RESPONDENTS

REPORTING HOUSEHOLD MEMBERS WITH

WHOM THEY LIVE'

\begin{tabular}{lcc}
\hline & $\begin{array}{c}\text { Females } \\
(\mathrm{n}=\mathbf{1 , 8 2 3})\end{array}$ & $\begin{array}{c}\text { Males } \\
(\mathrm{n}=\mathbf{1 , 7 8 8})\end{array}$ \\
\hline Parents & 62.0 & 83.3 \\
$\quad$ Mother & 47.3 & 65.3 \\
Father & 45.5 & 63.2 \\
$\quad$ Living with both & & \\
Siblings & 18.0 & 20.8 \\
$\quad$ Older brother & 44.7 & 59.9 \\
$\quad$ Younger brother & 11.2 & 13.8 \\
$\quad$ Older sister & 43.2 & 57.5 \\
$\quad$ Younger sister & & \\
Own Family & 25.4 & 7.8 \\
$\quad$ Husband or wife & 21.7 & 4.4 \\
Own children & 4.1 & 1.0 \\
In-laws & & \\
Others & 0.6 & 0.8 \\
Friends & 20.1 & 18.3 \\
Other & & \\
\hline
\end{tabular}

${ }^{\dagger}$ Multiple responses possible. 


\section{Parents' Marital Status}

Table 8 presents the marital status of respondents' parents. Overall, most of the respondents' parents were married at the time of the interview - 69\% for females and 73\% for males. Respondents aged 18-24 were more likely to have had one or more parent die, compared to younger respondents. This holds true for both female and male youth. There is very little variation in marital status of respondents' parents by region.

TABLE 8. PERCENT OF RESPONDENTS REPORTING PARENTAL MARITAL STATUS BY AGE AND REGION $^{\dagger}$

\begin{tabular}{|c|c|c|c|c|c|}
\hline & $\begin{array}{l}\text { Parents currently } \\
\text { married }\end{array}$ & $\begin{array}{c}1 \text { or more parent(s) } \\
\text { deceased }\end{array}$ & $\begin{array}{l}\text { Parents divorced/ } \\
\text { separated }\end{array}$ & $\begin{array}{l}\text { Don't know/ } \\
\text { other }\end{array}$ & Total $n$ \\
\hline \multicolumn{6}{|c|}{ Females } \\
\hline \multicolumn{6}{|l|}{ Age** } \\
\hline $12-14$ & 77.1 & 10.1 & 11.9 & 0.0 & 494 \\
\hline $15-17$ & 75.1 & 15.0 & 9.6 & 0.0 & 386 \\
\hline $18-24$ & 62.4 & 28.0 & 8.8 & 0.2 & 943 \\
\hline \multicolumn{6}{|l|}{ Region** } \\
\hline Tigray & 65.2 & 17.5 & 16.5 & 0.0 & 405 \\
\hline Amhara & 63.6 & 26.2 & 10.3 & 0.0 & 409 \\
\hline Oromia & 72.2 & 18.5 & 7.7 & 0.5 & 443 \\
\hline Benishangul-Gumuz & 65.1 & 23.3 & 11.6 & 0.0 & 189 \\
\hline SNNP & 77.5 & 18.0 & 3.7 & 0.0 & 377 \\
\hline Total & 69.1 & 20.4 & 9.8 & 0.1 & 1,823 \\
\hline \multicolumn{6}{|c|}{ Males } \\
\hline \multicolumn{6}{|l|}{ Age** } \\
\hline $12-14$ & 77.8 & 11.0 & 10.3 & 0.4 & 544 \\
\hline $15-17$ & 78.0 & 14.3 & 6.9 & 0.5 & 378 \\
\hline $18-24$ & 67.2 & 24.9 & 7.4 & 0.1 & 866 \\
\hline \multicolumn{6}{|l|}{ Region** } \\
\hline Tigray & 68.7 & 12.6 & 17.4 & 0.8 & 374 \\
\hline Amhara & 72.5 & 19.4 & 7.9 & 0.0 & 403 \\
\hline Oromia & 72.4 & 21.7 & 5.1 & 0.2 & 493 \\
\hline Benishangul-Gumuz & 70.2 & 17.7 & 11.3 & 0.7 & 141 \\
\hline SNNP & 78.2 & 19.4 & 2.1 & 0.0 & 377 \\
\hline Total & 72.7 & 18.4 & 8.2 & 0.3 & 1,788 \\
\hline
\end{tabular}

${ }^{\dagger}$ Row percentages may not add to $100 \%$ due to missing values.

${ }^{*} p<0.05 ; * \star p<0.01$ 


\section{Respondent Assets}

We asked respondents to tell us about their personal assets. Table 9 shows the proportion of respondents who reported having personal savings by age and region. The overall majority of females and males do not have personal savings. Only $12 \%$ of females and $16 \%$ of males had savings of their own. By age 18-24 years, female and male youth were significantly more likely to report having their own savings then younger respondents. By region, females living in Oromia were more likely to have savings than females living in other regions at $15 \%$. For males, those who live in SNNP were more likely to have savings than males who live in other regions.

TABLE 9. PERCENT OF RESPONDENTS WITH PERSONAL SAVINGS BY AGE AND REGION

\begin{tabular}{lcc:cc} 
& \multicolumn{2}{c}{ Females } & \multicolumn{2}{c}{ Males } \\
\cline { 2 - 5 } & $\%$ & Total n & $\%$ & Total n \\
\hline Age & $* *$ & & $* *$ & \\
$12-14$ & 5.1 & 494 & 7.2 & 544 \\
$15-17$ & 6.7 & 386 & 11.1 & 378 \\
$18-24$ & 17.7 & 943 & 24.1 & 866 \\
Region & $*$ & & $* *$ & \\
$\quad$ Tigray & 13.6 & 405 & 13.9 & 374 \\
$\quad$ Amhara & 10.8 & 409 & 11.4 & 403 \\
$\quad$ Oromia & 15.3 & 443 & 19.9 & 493 \\
Benishangul-Gumuz & 7.9 & 189 & 6.4 & 141 \\
$\quad$ SNNP & 9.5 & 377 & 22.5 & 377 \\
Total & 12.0 & 1,823 & 16.2 & 1,788 \\
\hline
\end{tabular}

$\star p<0.05 ; * \star p<0.01$

Table 10 presents respondents' ownership of a mobile phone by age and region. Close to 1 in 2 males $(47 \%)$ and 1 in 3 females (32\%) had a mobile phone. When looking at these data by age, older respondents irrespective of sex were significantly more likely to own a mobile phone. There are significant differences by region for ownership of a mobile phone for males only.

TABLE 10. PERCENT OF RESPONDENTS OWNING A MOBILE PHONE BY AGE AND REGION

\begin{tabular}{lcc}
\hline & Females & Males \\
\hline Age & $* *$ & $* *$ \\
$12-14$ & 7.1 & 11.8 \\
$15-17$ & 27.7 & 39.2 \\
$18-24$ & 47.3 & 72.1 \\
Region & & $* *$ \\
$\quad$ Tigray & 32.3 & 40.6 \\
Amhara & 28.9 & 39.0 \\
Oromia & 31.6 & 54.2 \\
$\quad$ Benishangul-Gumuz & 37.0 & 35.5 \\
$\quad$ SNNP & 34.2 & 55.7 \\
Total & 32.3 & 46.8 \\
\hline
\end{tabular}

${ }^{*} p<0.05 ;{ }^{*} p<0.01$ 


\section{SOCIAL SUPPORT AND AUTONOMY}

This study also explored aspects of youth social support and autonomy. We explored social support by asking the following three questions. Is there someone in your community who: 1) you could borrow money from if you needed to? 2) you could stay with if you encountered a problem in your current living situation? 3) would help you in case of a medical emergency? The results of these three questions are presented in Table 11 by age, marital status, and school status.

TABLE 11. PERCENT OF RESPONDENTS REPORTING VARIOUS SOCIAL SUPPORT ASPECTS BY AGE, MARITAL STATUS, AND SCHOOL STATUS

\begin{tabular}{|c|c|c|c|c|}
\hline & $\begin{array}{l}\text { Someone you } \\
\text { could borrow } \\
\text { money from }\end{array}$ & $\begin{array}{l}\text { Someone you } \\
\text { could stay with }\end{array}$ & $\begin{array}{l}\text { Someone to help } \\
\text { you in a medical } \\
\text { emergency }\end{array}$ & Total $n$ \\
\hline \multicolumn{5}{|c|}{ Females } \\
\hline Age & ** & & & \\
\hline $12-14$ & 48.0 & 69.4 & 76.1 & 494 \\
\hline $15-17$ & 63.5 & 73.6 & 76.4 & 386 \\
\hline $18-24$ & 63.7 & 74.0 & 80.9 & 943 \\
\hline Marital Status & ** & * & $* *$ & \\
\hline Single & 55.0 & 71.0 & 76.4 & 1,226 \\
\hline In union/married & 69.2 & 77.4 & 84.9 & 517 \\
\hline Widowed/divorced & 63.7 & 67.5 & 72.5 & 80 \\
\hline \multicolumn{5}{|l|}{ School Status } \\
\hline Out of school & 61.6 & 73.1 & 78.9 & 973 \\
\hline In school & 56.9 & 72.2 & 78.4 & 850 \\
\hline Total & 59.4 & 72.7 & 78.7 & 1,823 \\
\hline \multicolumn{5}{|c|}{ Males } \\
\hline Age & ** & & * & \\
\hline $12-14$ & 36.4 & 67.6 & 71.7 & 544 \\
\hline $15-17$ & 55.0 & 71.2 & 74.3 & 378 \\
\hline $18-24$ & 66.5 & 73.3 & 77.7 & 866 \\
\hline Marital Status & $\star *$ & ** & $\star *$ & \\
\hline Single & 52.7 & 70.0 & 73.9 & 1,620 \\
\hline In union/married & 80.1 & 84.8 & 90.1 & 151 \\
\hline Widowed/divorced & 43.8 & 56.3 & 62.5 & 16 \\
\hline School Status & ** & & & \\
\hline Out of school & 59.5 & 70.5 & 74.5 & 876 \\
\hline In school & 50.6 & 71.7 & 75.8 & 912 \\
\hline Total & 54.9 & 71.1 & 75.2 & 1,788 \\
\hline
\end{tabular}

${ }^{*} p<0.05 ; * * p<0.01$

At least one in two youth (both females and males interviewed) responded favorably to the three questions. Among all female youth, between $59 \%$ and $79 \%$ agreed that they could rely on someone to borrow money from, to stay with, and to help them in the case of an emergency. A similar range of percentages is observed among all male youth on these questions, ranging from $55 \%$ to $75 \%$.

Among female youth, there are significant differences by age for those who reported that they had someone from whom they could borrow money. Also, married female youth were significantly more likely to have someone that they could borrow money from, someone that they could stay with, and someone to help them in case of an emergency. There are no significant differences by schooling status across all three indicators. 
There are significant differences by age, marital status, and school status for male youth who have someone that they could borrow money from. Married male youth were significantly more likely to have someone to stay with. Married male youth were also significantly more likely to have someone to help them in case of a medical emergency.

A small proportion of respondents reported that they did not have someone they could rely on in any of these three instances. Seventeen percent of female youth responded "no" to all three questions, while 16\% of male youth responded "no" (data not shown).

We also asked respondents whether they require permission to leave the house or to attend community gatherings. The results of these questions are presented in Table 12. As both female and male youth grow older, they are significantly less likely to require permission to leave the house or to attend community gatherings. However, a slightly greater proportion of females than males between the ages of 18 and 24 years require permission to leave the house and to attend community gatherings.

TABLE 12. PERCENT OF RESPONDENTS NEEDING

PERMISSION TO LEAVE THE HOUSE OR ATTEND COMMUNITY GATHERINGS BY AGE, MARITAL STATUS, AND SCHOOL STATUS

\begin{tabular}{|c|c|c|c|}
\hline & $\begin{array}{l}\text { Permission to } \\
\text { leave the house }\end{array}$ & $\begin{array}{l}\text { Permission to } \\
\text { attend community } \\
\text { gathering }\end{array}$ & Total $n$ \\
\hline \multicolumn{4}{|c|}{ Females } \\
\hline Age & ** & & \\
\hline $12-14$ & 99.4 & 73.5 & 494 \\
\hline $15-17$ & 97.2 & 73.6 & 386 \\
\hline $18-24$ & 87.6 & 72.3 & 943 \\
\hline Marital Status & $* *$ & ** & \\
\hline Single & 96.3 & 73.5 & 1,226 \\
\hline In union/married & 87.4 & 74.9 & 517 \\
\hline Widowed/divorced & 73.8 & 51.2 & 80 \\
\hline School Status & $* *$ & * & \\
\hline Out of school & 88.2 & 70.9 & 973 \\
\hline In school & 98.1 & 75.2 & 850 \\
\hline Total & 92.8 & 72.9 & 1,823 \\
\hline \multicolumn{4}{|c|}{ Males } \\
\hline Age & ** & * & \\
\hline $12-14$ & 96.9 & 58.1 & 544 \\
\hline $15-17$ & 92.1 & 56.3 & 378 \\
\hline $18-24$ & 74.2 & 51.7 & 866 \\
\hline Marital Status & ** & ** & \\
\hline Single & 88.1 & 55.7 & 1,620 \\
\hline In union/married & 53.6 & 41.7 & 151 \\
\hline Widowed/divorced & 56.3 & 62.5 & 16 \\
\hline School Status & ** & ** & \\
\hline Out of school & 76.8 & 49.1 & 876 \\
\hline In school & 92.7 & 60.0 & 912 \\
\hline Total & 84.9 & 54.6 & 1,788 \\
\hline
\end{tabular}

$* p<0.05 ; * * p<0.01$
Almost all younger youth (aged 12-14 years), regardless of sex, ask for permission to leave the house. Similarly, single female and male youth require permission to both leave the house and attend community gatherings more so than married or widowed youth. Both female and male youth who are currently in school require permission to leave the house or permission to attend a community gathering compared to youth who are currently not in school.

Respondents were also asked from whom they needed permission before they left the house. Approximately $60 \%$ of female youth ask permission to leave the house from their mothers and $45 \%$ from their fathers (data not shown). Among married women, $82 \%$ require permission to leave from their husbands. Fewer married women (5\%) needed permission from in-laws.

Female youth (regardless of marital status) are also required to seek permission to attend community gatherings from their mothers, fathers, or husbands. Among married men, 37\% require permission from their wives to leave the house. 
Respondents were asked who in their family makes decisions about certain aspects of their lives, including health needs and school. Table 13 presents the results from these questions. Among female youth, more than half make decisions solely by themselves or with someone else. The proportion who reported that someone else makes decisions about certain aspects of their lives without their consultation was: $44 \%$ for decisions about school, $42 \%$ for decisions about who they should spend time with, $45 \%$ for decisions on where they can go, and 50\% for decisions about their health. This has implications for decision-making on whether or not to seek services. For decisions about how to spend money they earn, the percentage is lower at $21 \%$ because it includes those who do not earn any money.

\section{TABLE 13. PERCENTAGE DISTRIBUTION OF FEMALE AND MALE RESPONDENTS INVOLVED IN DECISION-MAKING ON VARIOUS MATTERS ${ }^{\dagger}$}

\begin{tabular}{|c|c|c|c|}
\hline & Myself & $\begin{array}{c}\text { Myself and } \\
\text { someone else }\end{array}$ & $\begin{array}{c}\text { Someone else } \\
\text { only }\end{array}$ \\
\hline \multicolumn{4}{|c|}{ Females $(n=1,823)$} \\
\hline \multicolumn{4}{|l|}{ Decisions about: } \\
\hline Own health & 9.4 & 40.8 & 49.8 \\
\hline School-related matters & 16.3 & 39.8 & 43.7 \\
\hline How to spend money earned ${ }^{\dagger \dagger}$ & 15.3 & 32.7 & 21.3 \\
\hline Who to spend time with & 20.8 & 37.2 & 41.7 \\
\hline Where to go & 15.7 & 39.0 & 45.2 \\
\hline \multicolumn{4}{|c|}{ Males $(n=1,788)$} \\
\hline \multicolumn{4}{|l|}{ Decisions about: } \\
\hline Own health & 11.9 & 42.4 & 45.6 \\
\hline School-related matters & 19.5 & 37.1 & 43.2 \\
\hline How to spend money earned ${ }^{\dagger \dagger}$ & 26.3 & 30.5 & 21.5 \\
\hline Who to spend time with & 30.3 & 34.2 & 35.4 \\
\hline Where to go & 26.0 & 35.2 & 38.6 \\
\hline
\end{tabular}

${ }^{+}$Row percentages may not add to $100 \%$ due to missing values.

${ }^{+\dagger}$ Row percentages may not add to $100 \%$ because denominator includes those who did not earn money of their own.

Among male youth, the proportion reporting that someone else makes decisions about certain aspects of their lives was: $46 \%$ for decisions about their health, $43 \%$ for decisions about school, $35 \%$ for decisions about who they should spend time with, and $39 \%$ for decisions on where they can go. Twenty-two percent said that someone else made decisions about how they spent money that they earned.

\section{BASIC HEALTH SERVICES AND YOUTH FRIENDLY SERVICES}

For both basic health services and youth friendly services, respondents were provided an explanation of what these services included. For basic health services, respondents were told basic health services include treatment for common illnesses like diarrhea or malaria. For youth friendly services, respondents were told that youth friendly services are especially designed for individuals of your age. Youth friendly services try to meet the specific health needs of youth.

\section{Preferences for Basic Health Service Characteristics}

We asked all respondents to rate characteristics of health services and providers that they valued on a 4-point scale (with 4 being very important and 1 being very unimportant). We reported the very important responses in Table 14. 
TABLE 14. PERCENTAGE DISTRIBUTION OF FEMALE AND MALE RESPONDENTS' BASIC HEALTH SERVICE PREFERENCES ${ }^{\dagger}$

\begin{tabular}{lcc}
\hline \multicolumn{1}{c}{ Basic Health Service Preferences } & $\begin{array}{c}\text { Females } \\
(\mathbf{n = 1 , 8 2 3})\end{array}$ & $\begin{array}{c}\text { Males } \\
(\mathbf{n = 1 , 7 8 8})\end{array}$ \\
\hline Health services near place of residence & 88.3 & 93.1 \\
Low cost or free services & 84.4 & 87.3 \\
Friendly staff & 84.0 & 86.6 \\
All services are available at the same health facility & 81.6 & 80.9 \\
Hours that are convenient & 81.5 & 78.2 \\
Short waiting times & 81.0 & 80.9 \\
Provider is not rushed during consultation & 80.1 & 78.6 \\
Information kept confidential by providers & 79.1 & 74.4 \\
Full range of contraceptives are available on the day of visit & 68.9 & - \\
Seen by a provider of the same sex & 60.8 & 51.3 \\
Only other clients present are of the same sex & 33.2 & 35.8 \\
No one from the community would know of visit & 12.2 & 18.9 \\
\hline
\end{tabular}

${ }^{\dagger}$ Multiple responses possible.

Overall, the overwhelming majority of female and male youth reported that the following aspects of health services very important to them: 1) health services near place of residence, 2) low cost or free services, 3) friendly staff, 4) all services available at the same health facility, 5) convenient hours, and 6) short waiting times. In terms of provider characteristics, female and male youth both indicated that they would like to see providers who do not rush during the consultation and who keep their information confidential. Most also preferred to be seen by a provider of the same sex.

Fewer were concerned about being seen by others in the community at the health center (probably because the questions were about basic health services as opposed to reproductive health or family planning services), but more preferred that the other clients were of the same sex. Asked of female youth only, $69 \%$ would like a full range of contraceptive methods available on the day of their visit. 


\section{Knowledge and Source of Basic Health Services and Youth Friendly Services}

In the following section, results are presented on knowledge and use of basic health services and youth friendly services. The study team decided to ask about both types of services to compare young people's perceptions and use of youth friendly services (a more specialized type of service) to basic health perceptions and services. When possible, we present these results side-by-side for comparison purposes.

The overwhelming majority of youth interviewed had not heard of youth friendly services (Table 15: 93\% for females and $92 \%$ for males). It is important to note that awareness of youth friendly services may reflect name recognition of youth friendly services instead of actual knowledge of these services.

\begin{tabular}{|c|c|c|}
\hline & $\begin{array}{l}\text { Basic health } \\
\text { services }\end{array}$ & $\begin{array}{c}\text { Youth friendly } \\
\text { services }\end{array}$ \\
\hline \multicolumn{3}{|c|}{ Females $(n=1,823)$} \\
\hline Hospital & 39.3 & 1.0 \\
\hline Private clinic & 44.3 & 0.5 \\
\hline Health post & 25.8 & 0.9 \\
\hline Health center & 90.9 & 4.4 \\
\hline Youth center & 0.4 & 0.3 \\
\hline Youth friendly services & 0.1 & - \\
\hline Peer educator & 0.1 & 0.3 \\
\hline Traditional healer & 1.7 & 0.0 \\
\hline Drug vendor/pharmacist & 3.0 & 0.2 \\
\hline FGAE & 0.7 & 1.3 \\
\hline Other & 0.5 & 1.2 \\
\hline Don't know & 0.4 & 0.2 \\
\hline Has not heard of YFS & - & 92.8 \\
\hline \multicolumn{3}{|c|}{ Males $(n=1,788)$} \\
\hline Hospital & 40.5 & 1.3 \\
\hline Private clinic & 41.8 & 0.3 \\
\hline Health post & 30.8 & 1.2 \\
\hline Health center & 87.6 & 5.4 \\
\hline Youth center & 0.2 & 0.8 \\
\hline Youth friendly services & 0.3 & - \\
\hline Peer educator & 0.0 & 0.6 \\
\hline Traditional healer & 3.1 & 0.0 \\
\hline Drug vendor/pharmacist & 7.6 & 0.1 \\
\hline FGAE & 1.4 & 1.8 \\
\hline Other & 0.6 & 0.3 \\
\hline Don't know & 0.5 & 0.2 \\
\hline Has not heard of YFS & - & 91.8 \\
\hline
\end{tabular}

As a result of this low awareness, the source of youth friendly services is very low overall as seen in Table 15. According to the 2006 guidelines put forward by FMOH (see page 2), youth friendly services should be available at a wide range of health facility types. Pathfinder's Integrated Family Health Program (IFHP) supported facilities, however, focused on supporting youth friendly services at health centers and creating demand through peer educators. FGAE, the IPPF affiliate, supported youth friendly services at standalone youth centers. Only $4 \%$ of female youth and $5 \%$ of male youth reported that they could obtain youth friendly services from health centers. Fewer youth knew that FGAE or youth centers offered youth friendly services. A negligible number knew of peer educators as a source of referrals for youth friendly services. In comparison, the majority of youth reported health centers as the source of basic health services $(91 \%$ for females and $88 \%$ for males), followed by private clinics ( $44 \%$ for females and $42 \%$ for males) and hospitals (39\% for females and $41 \%$ for males).

${ }^{\dagger}$ Multiple responses possible. 
Youth who had heard of youth friendly services were asked what types of services are available. Table 16 presents these results for both female and male youth. Among females, the service mentioned most often as available is HIV counseling, testing, and treatment. A slightly greater number of male youth knew that this service was available.

The second most mentioned service is contraceptive services. A smaller number of female and male youth reported that sexual and reproductive health counseling is available at YFS.

TABLE 16. NUMBER OF FEMALE AND MALE RESPONDENTS

WITH KNOWLEDGE OF SERVICES OFFERED AT YOUTH FRIENDLY SERVICES ${ }^{\dagger}$

\begin{tabular}{lcc}
\hline & Females & Males \\
\cline { 2 - 3 } & $\mathrm{n}$ & $\mathrm{n}$ \\
\hline Have heard of YFS & 131 & 147 \\
HIV counseling, testing, treatment & 81 & 116 \\
Contraceptive services & 69 & 75 \\
Sexual and reproductive health counseling & 42 & 61 \\
Sexually transmitted infection (STI) & 19 & 28 \\
counseling, testing, treatment & 16 & - \\
Maternal health services & 15 & 22 \\
Malaria & 13 & - \\
Prevention of Mother to Child Transmission & & \\
(PMTCT) & 11 & 10 \\
Gender-based violence (GBV) counseling, & 7 & 10 \\
treatment, referral & 5 & 13 \\
Child immunizations & 4 & - \\
Nutrition counseling & 3 & 4 \\
Pregnancy testing & 1 & - \\
Tuberculosis & 1 & - \\
Gynecological exams & 1 & 0 \\
Postabortion care & 4 & 4 \\
Acute respiratory infections/pneumonia & 992 & \\
Other & & \\
Don't know & & \\
Never heard of YFS & & \\
\hline
\end{tabular}

${ }^{\dagger}$ Multiple responses possible. 


\section{Utilization of Basic Health Services and Youth Friendly Services}

We asked respondents to tell us about their use of basic health services and youth friendly services. Table 17 presents respondents who have used basic health services in the past year and Table 18 presents respondents who have never heard of, never used, and ever used youth friendly services.

Overall, youth have low utilization of health services whether it is for basic health or youth friendly services. Only $37 \%$ of female youth and $39 \%$ of male youth used basic health services in the past year, while $2 \%$ of female youth and $4 \%$ of male youth have ever used youth friendly services. Youth, however, may have visited a YFS site but not realized that they had. It is important to note that youth may have used YFS services without realizing it (see page 40 for analyses of YFS versus non-YFS service utilization that match the facility name a respondent reported visiting to the regional health bureau's list of YFS sites).

TABLE 17. PERCENT OF RESPONDENTS WHO USED BASIC HEALTH SERVICES BY AGE, REGION, DISTANCE TO A YFS SITE

\begin{tabular}{lcc:cc} 
& \multicolumn{2}{c}{ Females } & \multicolumn{2}{c}{ Males } \\
\cline { 2 - 5 } & $\begin{array}{c}\text { Used BHS in } \\
\text { past year }\end{array}$ & Total $\mathrm{n}$ & $\begin{array}{c}\text { Used BHS in } \\
\text { past year }\end{array}$ & Total $\mathrm{n}$ \\
\hline Age & $* *$ & & $* *$ & \\
$12-14$ & 27.7 & 494 & 32.2 & 544 \\
$15-17$ & 32.1 & 386 & 36.2 & 378 \\
18-24 & 43.9 & 943 & 43.5 & 866 \\
Region & $* *$ & & $* *$ & \\
Tigray & 24.9 & 405 & 26.1 & 374 \\
Amhara & 39.1 & 409 & 43.4 & 403 \\
Oromia & 35.7 & 443 & 36.7 & 493 \\
Benishangul-Gumuz & 38.6 & 189 & 40.4 & 141 \\
SNNP & 48.5 & 377 & 47.2 & 377 \\
Distance to facility & $* *$ & & & \\
$<5$ km from non-YFS & 36.0 & 343 & 43.4 & 362 \\
$<5$ km from YFS & 41.2 & 735 & 38.7 & 656 \\
$5-10$ km from YFS & 32.9 & 745 & 36.1 & 770 \\
Total & 37.0 & 1,823 & 38.5 & 1,788 \\
\hline
\end{tabular}

${ }^{*} p<0.05 ; * * p<0.01$

Use of any service type increases with age for both females and males. In addition, use of any service is greatest among those living in SNNP, followed by Amhara and Benishangul-Gumuz. The lowest levels of youth utilization of services are seen in Tigray for female and male youth.

Table 18 also shows the outcomes by residential distance to a YFS site or a comparison facility. As hypothesized, female and male youth who live less than $5 \mathrm{~km}$ from a YFS site are more likely to have heard of youth friendly services and to have used these services compared to youth who live 5-10 km from a YFS site and youth who live $<5 \mathrm{~km}$ from a non-YFS site. It is not surprising that the overall proportion of both female and youth who have heard of youth friendly services is low. Youth friendly services are not advertised as such, so therefore we did not expect there to be a high proportion of youth who recognized the term youth friendly services.

Respondents who reported using youth friendly services were asked what types of services they used. The services mentioned most often include SRH counseling and HIV counseling, testing, and treatment. Of those who reported having used youth friendly services, we calculated the proportion that have used more 
than one service. Among the 38 females who used youth friendly services, $45 \%$ used more than one service (data not shown). Among the 65 males who used youth friendly services, $57 \%$ use more than one service (data not shown).

TABLE 18. PERCENT OF RESPONDENTS WHO USED YOUTH

FRIENDLY SERVICES BY AGE, REGION, DISTANCE TO A YFS SITE

\begin{tabular}{|c|c|c|c|c|}
\hline & $\begin{array}{c}\text { Never heard of } \\
\text { YFS }\end{array}$ & $\begin{array}{c}\text { Heard of YFS but } \\
\text { never used }\end{array}$ & Ever used YFS & Total $\mathrm{n}$ \\
\hline \multicolumn{5}{|c|}{ Females } \\
\hline \multicolumn{5}{|l|}{ Age** } \\
\hline $12-14$ & 96.8 & 3.0 & 0.2 & 494 \\
\hline $15-17$ & 93.3 & 4.9 & 1.8 & 386 \\
\hline $18-24$ & 90.6 & 6.3 & 3.2 & 943 \\
\hline \multicolumn{5}{|l|}{ Region** } \\
\hline Tigray & 98.3 & 1.5 & 0.2 & 405 \\
\hline Amhara & 91.0 & 6.4 & 2.7 & 409 \\
\hline Oromia & 94.1 & 3.8 & 2.0 & 443 \\
\hline Benishangul-Gumuz & 95.8 & 2.1 & 2.1 & 189 \\
\hline SNNP & 85.9 & 10.6 & 3.4 & 377 \\
\hline \multicolumn{5}{|l|}{ Distance to facility** } \\
\hline$<5 \mathrm{~km}$ from non-YFS & 98.5 & 1.5 & 0.0 & 343 \\
\hline$<5 \mathrm{~km}$ from YFS & 86.5 & 9.1 & 4.4 & 735 \\
\hline $5-10 \mathrm{~km}$ from YFS & 96.4 & 2.8 & 0.8 & 745 \\
\hline Total & 92.8 & 5.1 & 2.1 & 1,823 \\
\hline \multicolumn{5}{|c|}{ Males } \\
\hline \multicolumn{5}{|l|}{ Age** } \\
\hline $12-14$ & 97.8 & 1.5 & 0.7 & 544 \\
\hline $15-17$ & 92.9 & 5.0 & 2.1 & 378 \\
\hline $18-24$ & 87.5 & 6.4 & 6.1 & 866 \\
\hline \multicolumn{5}{|l|}{ Region** } \\
\hline Tigray & 95.2 & 2.9 & 1.9 & 374 \\
\hline Amhara & 88.6 & 6.0 & 5.5 & 403 \\
\hline Oromia & 97.6 & 0.8 & 1.6 & 493 \\
\hline Benishangul-Gumuz & 92.2 & 2.8 & 5.0 & 141 \\
\hline SNNP & 84.1 & 10.3 & 5.6 & 377 \\
\hline \multicolumn{5}{|l|}{ Distance to facility** } \\
\hline$<5 \mathrm{~km}$ from non-YFS & 96.7 & 1.6 & 1.6 & 362 \\
\hline$<5 \mathrm{~km}$ from YFS & 84.6 & 8.1 & 7.3 & 656 \\
\hline $5-10 \mathrm{~km}$ from YFS & 95.6 & 3.0 & 1.4 & 770 \\
\hline Total & 91.8 & 4.6 & 3.6 & 1,788 \\
\hline
\end{tabular}

${ }^{*} p<0.05 ;{ }^{*} p<0.01$ 


\section{Youth Friendly Service User Profile}

Table 19 provides a profile of the respondents who reported that they did use youth friendly services. The percentages presented in this table are out of 38 females and 65 males. The majority of users are older: $79 \%$ of female users are ages $18-24$ years, while $82 \%$ of male users are ages $18-24$ years. For female youth, about half of users are single and the other half are married. For males, however, the majority of users are single $(82 \%)$. Male and female users tend to at least have some amount of primary education or more, and most are currently not in school. In terms of religion, both female and male Muslims tend to be using youth friendly services slightly more than Orthodox Christians.

In terms of distance from a YFS site or comparison site, as expected the greatest proportion of female and male youth who used youth friendly services resided within $5 \mathrm{~km}$ of a YFS site $(84 \%$ for females and $74 \%$ for males). A smaller percentage of youth who used youth friendly services resided 5-10 kms from a YFS site at $16 \%$ and $17 \%$ for females and males, respectively. Finally, as expected very few female and male youth used youth friendly services who resided within $5 \mathrm{~km}$ of a comparison site.

TABLE 19. PERCENTAGE DISTRIBUTION OF YFS USERS BY SELECT DEMOGRAPHIC CHARACTERISTICS ${ }^{\dagger}$

\begin{tabular}{|c|c|c|}
\hline & $\begin{array}{c}\text { Females } \\
(n=38)\end{array}$ & $\begin{array}{l}\text { Males } \\
(n=65)\end{array}$ \\
\hline \multicolumn{3}{|l|}{ Age } \\
\hline $12-14$ & 2.6 & 5.2 \\
\hline $15-17$ & 18.4 & 12.3 \\
\hline $18-24$ & 79.0 & 81.5 \\
\hline \multicolumn{3}{|l|}{ Marital Status } \\
\hline Single & 44.7 & 81.5 \\
\hline In union/married & 52.6 & 16.9 \\
\hline Widowed/divorced/separated & 2.6 & 1.5 \\
\hline \multicolumn{3}{|l|}{ Educational Attainment } \\
\hline Never attended school & 10.5 & 1.5 \\
\hline Primary & 34.2 & 50.8 \\
\hline Secondary & 44.7 & 30.8 \\
\hline Technical/Vocational & 5.2 & 13.8 \\
\hline Higher & 5.2 & 3.1 \\
\hline \multicolumn{3}{|l|}{ School Status } \\
\hline In school & 39.5 & 40.0 \\
\hline Out of school/never attended & 60.5 & 60.0 \\
\hline \multicolumn{3}{|l|}{ Religion } \\
\hline Orthodox Christian & 42.1 & 38.5 \\
\hline Muslim & 44.7 & 47.7 \\
\hline Protestant & 13.2 & 10.8 \\
\hline Catholic & 0.0 & 3.0 \\
\hline Other & 0.0 & 0.0 \\
\hline \multicolumn{3}{|l|}{ Distance to facility } \\
\hline$<5 \mathrm{~km}$ from non-YFS & 0.0 & 9.2 \\
\hline$<5 \mathrm{~km}$ from YFS & 84.2 & 73.9 \\
\hline $5-10 \mathrm{~km}$ from YFS & 15.8 & 16.9 \\
\hline
\end{tabular}

${ }^{+}$Column percentages may not add to $100 \%$ due to missing values. 


\section{FAMILY PLANNING SERVICES}

\section{Contraceptive Knowledge}

We asked all respondents to list all contraceptive methods that they knew, and for those that were not mentioned, the method was described. Spontaneous and probed responses are combined and reported in Table 20. Overall, only 5\% of females and 6\% of males did not know of any contraceptive methods. Knowledge of any modern method is higher than any traditional method for both female and male youth. The methods that appear to be more widely known are: injectables ( $93 \%$ females, $89 \%$ males), pills ( $88 \%$ females, $84 \%$ males), male condoms ( $77 \%$ females, $89 \%$ males) and implants ( $75 \%$ females, $52 \%$ males).

Method knowledge increased with age for all methods among both female and male youth. Contraceptive method knowledge is lowest in Oromia compared to the other regions for females and males. The median number of methods known by females and males is five (data not shown). 


\begin{tabular}{|c|c|c|c|}
\hline 言童 & 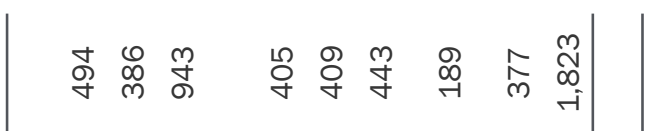 & 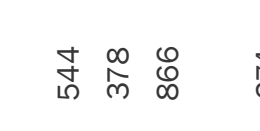 & 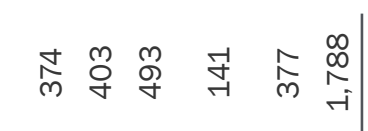 \\
\hline$\frac{0}{\frac{2}{2}}$ & 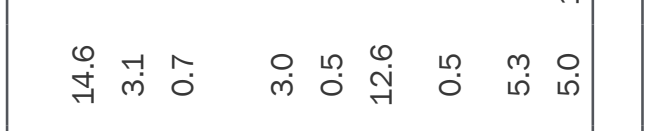 & 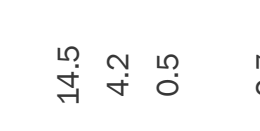 & 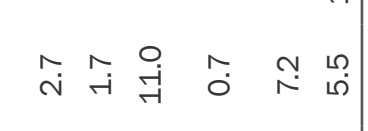 \\
\hline $1=$ & 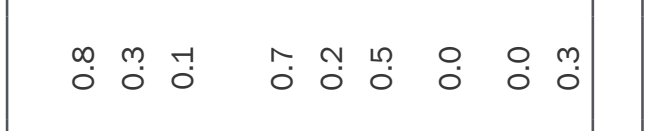 & 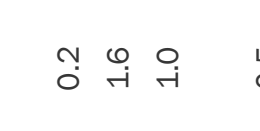 & 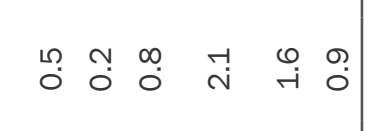 \\
\hline 雨 & 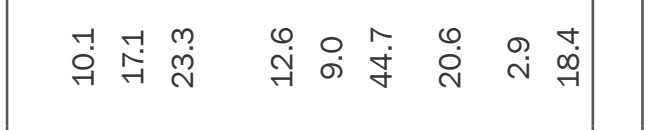 & 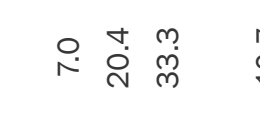 & 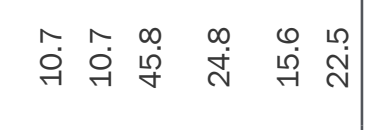 \\
\hline & 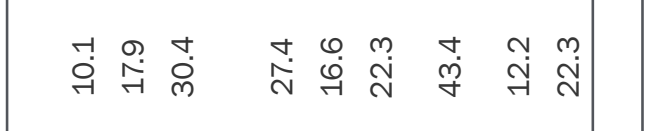 & 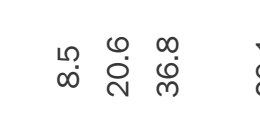 & 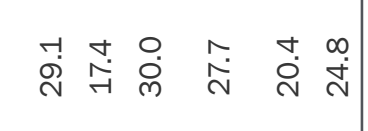 \\
\hline 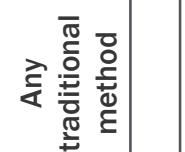 & 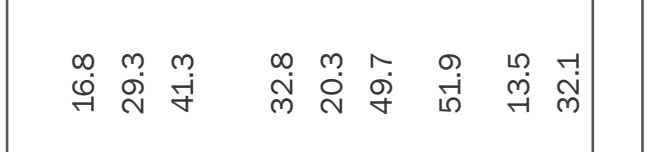 & 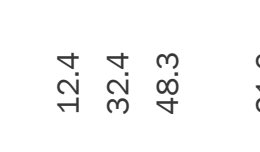 & 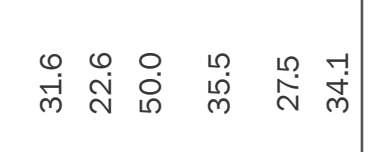 \\
\hline 咅 & 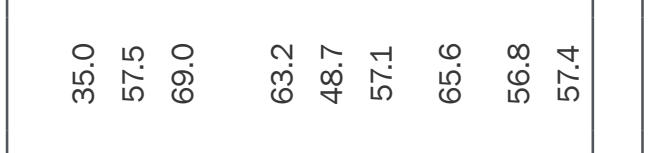 & 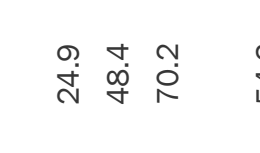 & 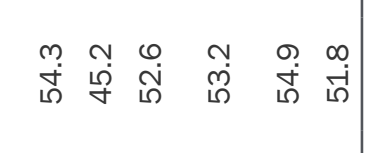 \\
\hline$=\bar{z}$ & 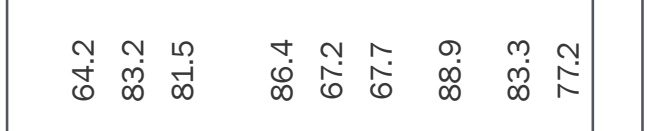 & 采学咅 & 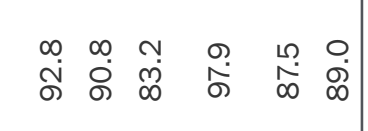 \\
\hline$\overline{\bar{a}}$ & 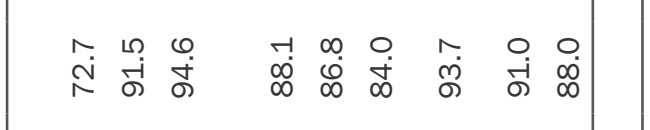 & 总露最 & 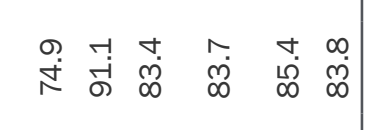 \\
\hline 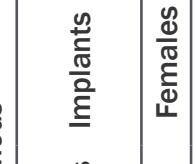 & 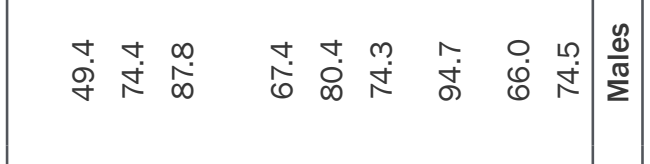 & 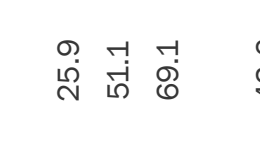 & 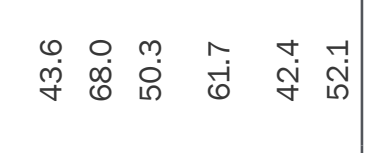 \\
\hline & 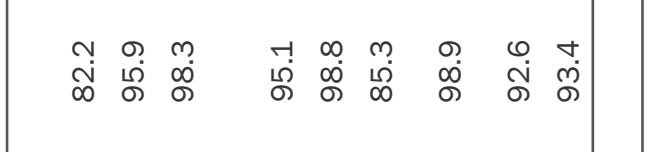 & 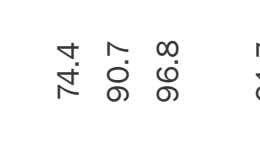 & 곻욤옳 \\
\hline e & 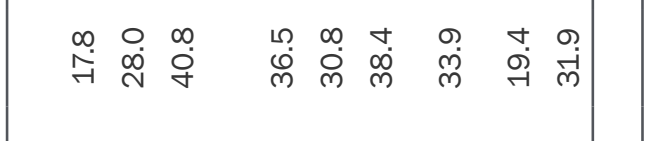 & 品品莦 & 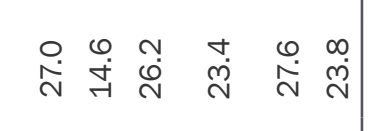 \\
\hline$\frac{g}{n}$ & 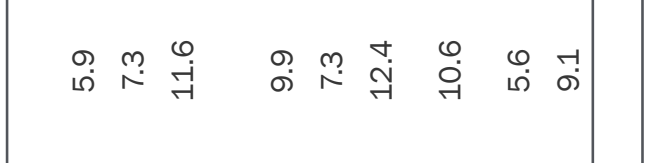 & 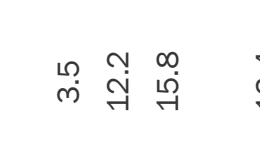 & 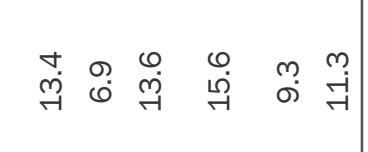 \\
\hline & 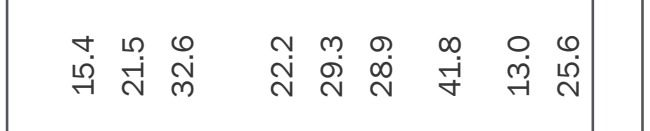 & 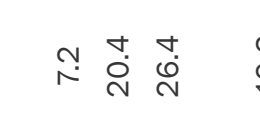 & 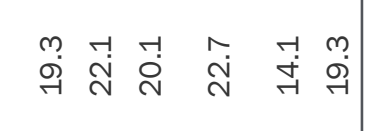 \\
\hline 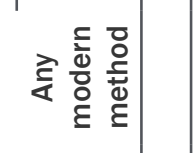 & 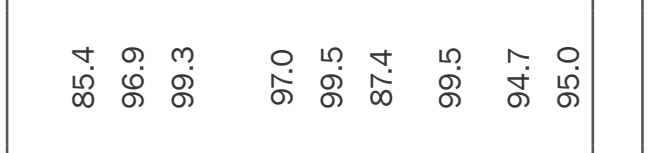 & 喽器器 & 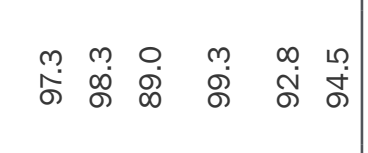 \\
\hline & 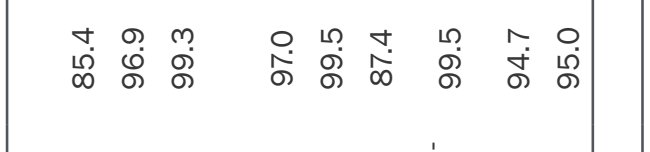 & 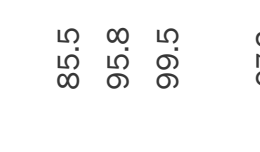 & 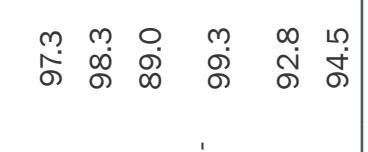 \\
\hline
\end{tabular}




\section{Source of Contraceptive Information}

Table 21 shows the source of contraceptive information by age and region for female and male youth. Overall, female youth receive contraceptive information from parents/relatives (38\%), peers (40\%), teachers $(31 \%)$, and health providers $(20 \%)$. Of all the media channels, the radio $(11 \%)$ was identified more frequently as a source of contraceptive information than the television $(9 \%)$ or a newspaper $(2 \%)$. A negligible proportion of female youth identified peer educators $(<1 \%)$ as their source of contraceptive information. However, given that peer educators are peers by definition, respondents may not have known that they were receiving information from a peer educator. Respondents may have therefore reported the source of contraceptive information as peers when they were in fact peer educators. Roughly $40 \%$ of female youth reported peers as their source of contraceptive information. Among 18-24 year olds, 13\% identified Health Extension Workers (HEWs) as a source of contraceptive information.

Looking at these results by age, as age increases, teachers and parents/relatives are less likely to be a source of information, while health providers and peers are more likely to be a source of information. There are also some notable differences between sources of contraceptive information by region. In Tigray, teachers (58\%) appear to be the most likely source for information, while in Amhara and Benishangul-Gumuz it is parents/relatives and in Oromia and SNNP it is peers. Media appears to be more relevant as a contraceptive information source in Oromia.

For male youth, we also asked about the source of contraceptive information. These results are also presented in Table 20 by age and region. Males primarily receive information about contraceptive methods from peers $(53 \%)$, followed by teachers $(40 \%)$ and the radio $(25 \%)$. As male youth grow older, they receive more contraceptive information from the media (e.g., television and radio) and from health providers and peers. Male youth receive less information from teachers as they grow older. There is no difference in parents/relatives as a source of contraceptive information by age.

In terms of region, the majority of males in Benishangul-Gumuz receive information from their peers $(79 \%)$. In addition, at least $50 \%$ of males reported receiving contraceptive information from peers in Amhara and SNNP. In Tigray and SNNP, over half of respondents also reported their teachers as a source of contraceptive information. As with females, the media appears to play the strongest role in providing contraceptive information in Oromia. 


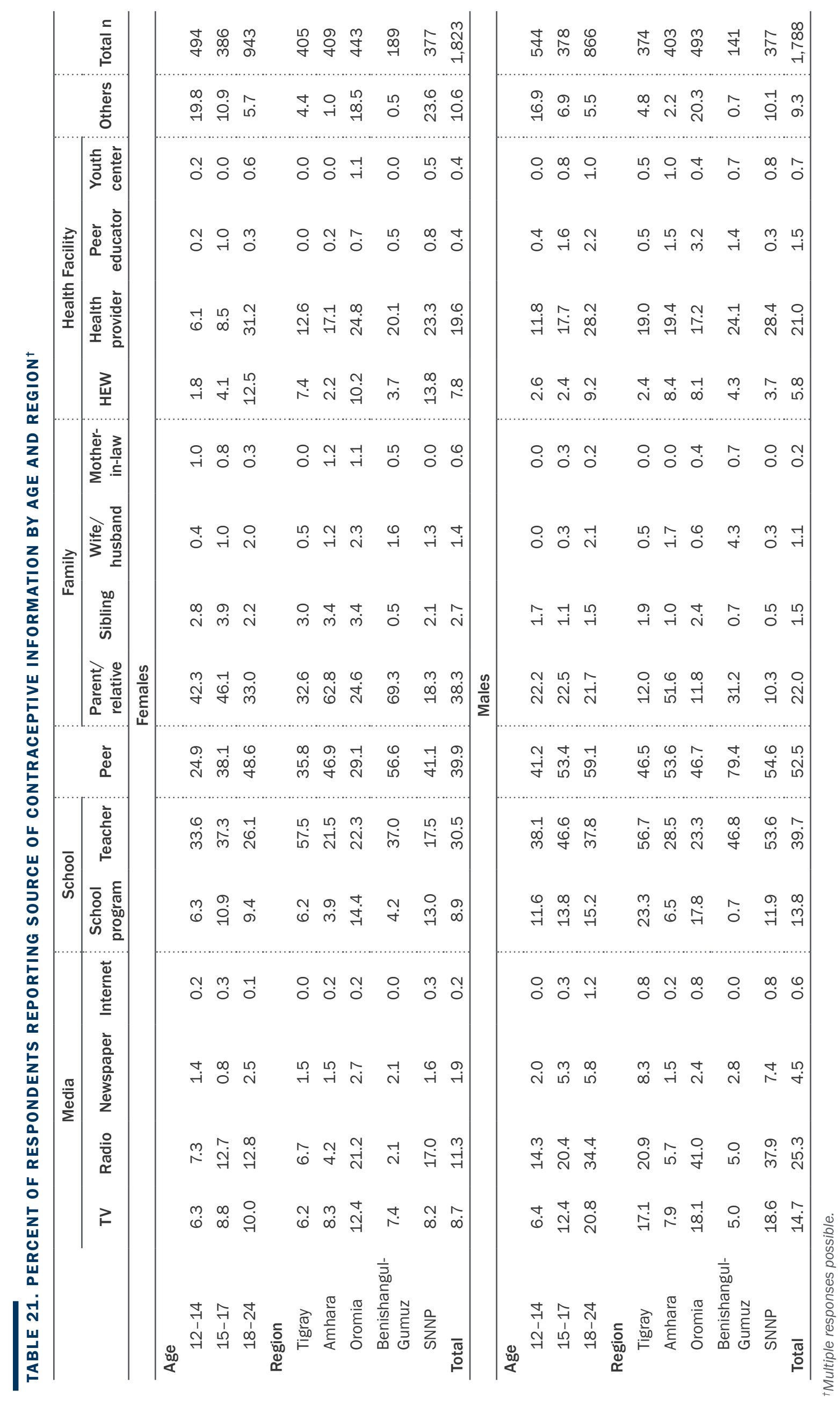




\section{Knowledge of Source of Contraceptive Services}

Table 22 shows the proportion of female and male youth who indicated places where they could receive contraceptive services in their community. This was a nonprompted multiple-response question. Eleven percent of female youth could not identify a place where contraceptive services could be obtained and this was more likely among the 12-14 year olds (24\%) who were less likely to know of a place than 18-24 year olds $(3 \%)$. In Oromia, 1 in 5 youth (21\%) could not name a location. Female youth reported that they could receive contraceptive services at a health center $(79 \%)$, followed by a health post $(33 \%)$ and a private clinic $(24 \%)$. As we would expect, as respondents' age increases their overall knowledge of places where they can obtain contraception also increases. Very small numbers of respondents reported a youth friendly service $(<1 \%)$ as sources for contraceptive methods. No one mentioned HEWs as a source of contraceptive services.

Female youth's knowledge of places where they can obtain contraceptive services by region varies. While the majority of respondents across all the regions reported health center, in Oromia and SNNP respondents also reported a health post. Knowledge of private clinics for contraceptives is greatest in Amhara (39\%) and Beninshangual-Gumuz (30\%).

For male youth, we asked about their knowledge of places where they could obtain condoms. These results are presented in Table 22. One in five (20\%) respondents could not name a place where they could obtain condoms. Lack of knowledge decreased among older respondents compared to younger respondents $38 \%$ versus $9 \%$ ). In Tigray, $35 \%$ of male respondents did not know a place where condoms were available.

The majority of male youth reported a health center as a place to get condoms $(57 \%)$, followed by a health post $(21 \%)$, private clinic $(16 \%)$, and then a hospital $(12 \%)$. Eleven percent of respondents reported a drug vendor/pharmacist for condoms. Twenty-seven percent of respondents reported "other" and when we took a closer look at the "other" category, we found that many respondents reported "shop" as a place to get condoms. One in five male youth could not name where they could obtain condoms. This lack of knowledge was more likely among 12-14 year olds compared to the older youth. 


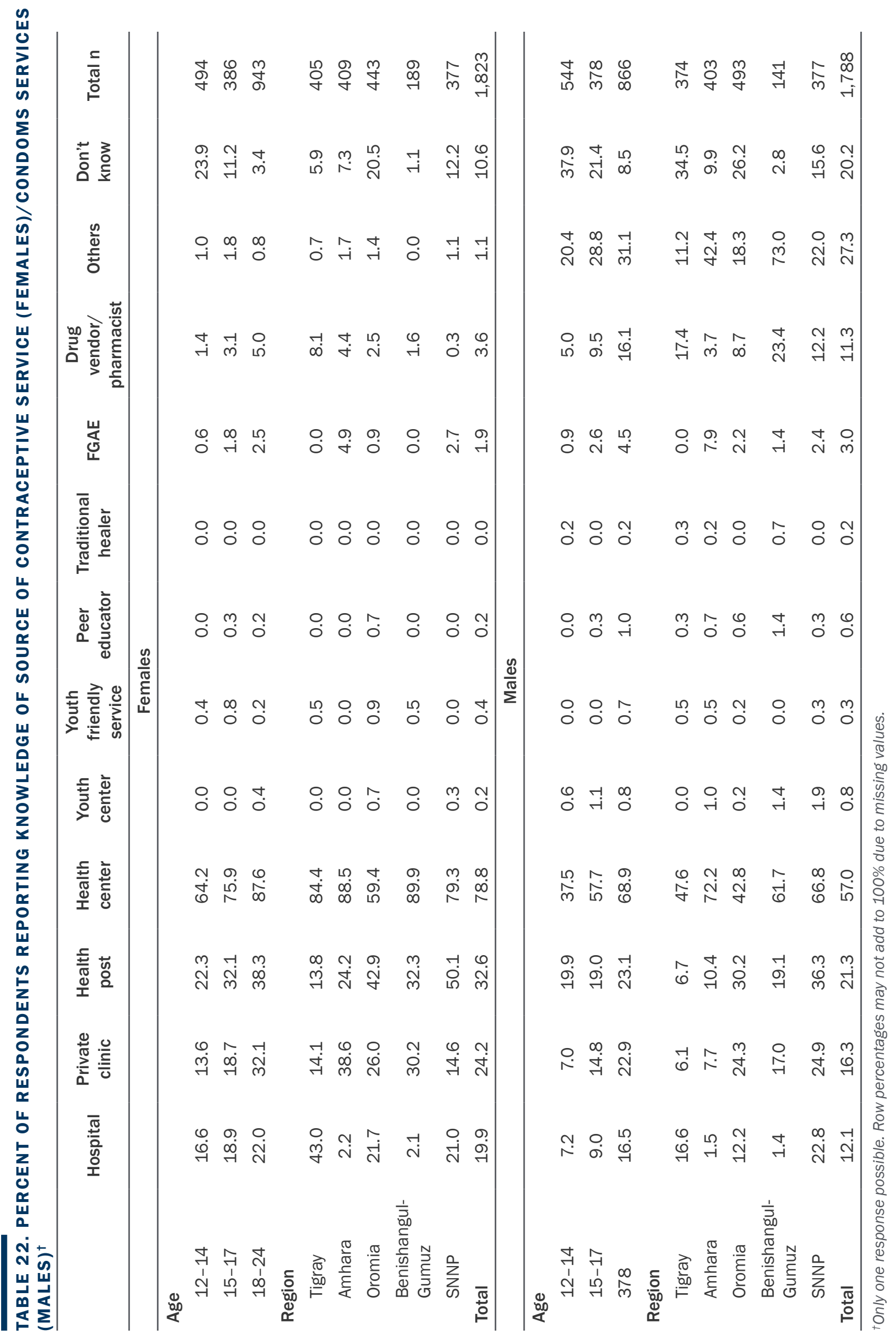




\section{Facility and Provider Preferences for Family Planning Services}

We asked female youth who had heard of at least one contraceptive method what their preferred location would be to obtain contraceptive services. The analogous question for male youth was about condom services. This was an unprompted question and only one response was possible. Table 23 provides the responses.

Most female youth reported that they would prefer to go to a health center for contraceptive services $(62 \%)$, followed by a health post $(17 \%)$, a hospital $(9 \%)$, and a private clinic $(5 \%)$. While youth friendly services was negligible as a preferred place for services, it is important to keep in mind that the majority of youth had not heard of YFS.

By region, female youth living in Oromia and SNNP are less likely to indicate a health center $38 \%$ and $60 \%$, respectively) as the preferred place for contraceptive services compared to the other regions. These youth were more likely to indicate a health post. Hospitals were the preferred place to obtain contraceptives for approximately 1 in 10 youth (19\%) living in Tigray.

Among male youth, approximately 1 in 2 youth (49\%) reported a health center as their preferred place to obtain condoms followed by a health post (15\%). Fewer 12-14 year olds preferred health centers compared to 15-17 and 18-24 year olds. In all regions, the males would prefer to get condoms from health centers. 


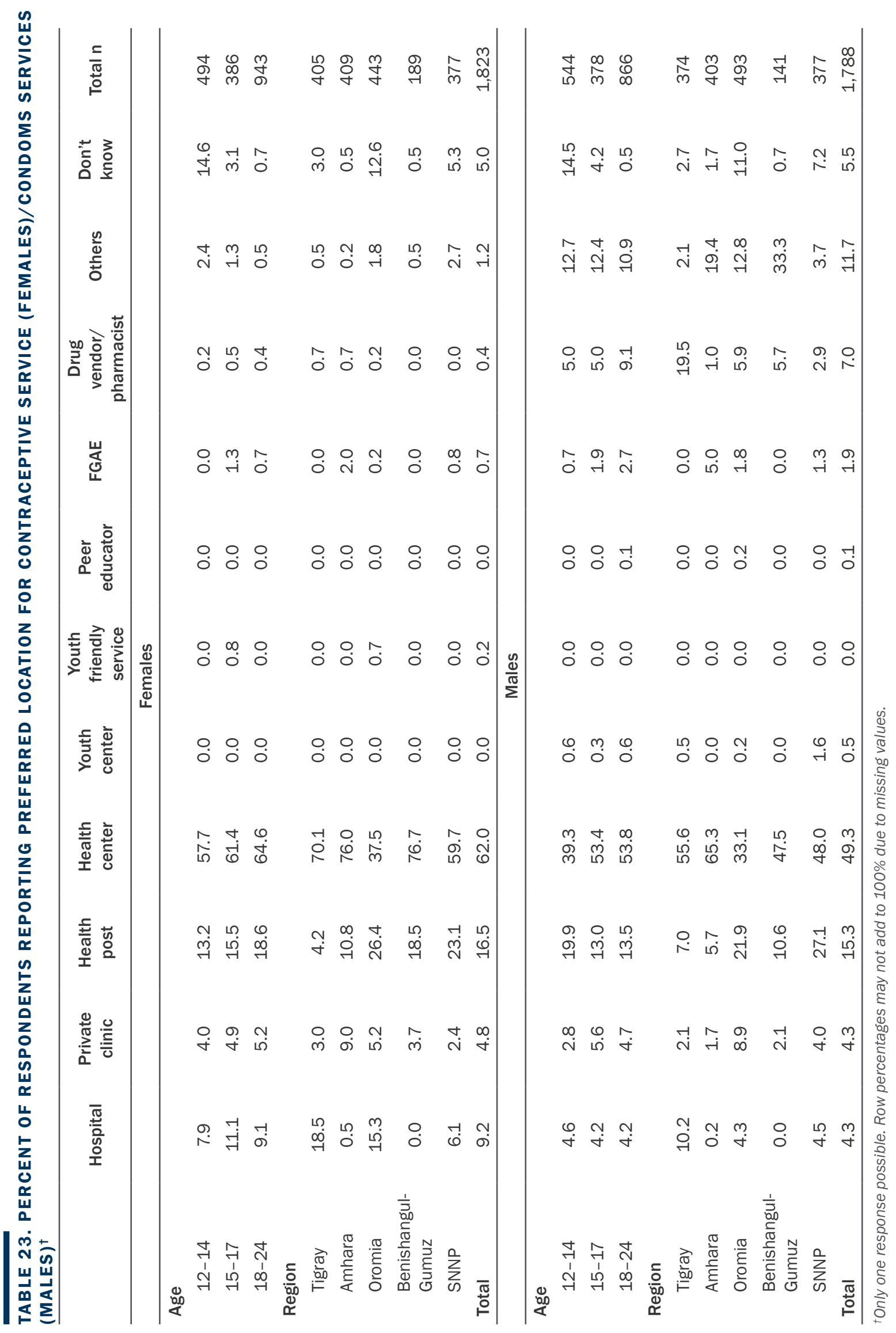


Table 24 presents reasons why youth selected the locations in Table 23 for contraceptive services or condoms. We selected the top three places preferred for services and presented the top three reasons. The top three places for female youth were health center, health post, and hospital. The same leading two preferred places were cited by males for condoms, but the third place was drug vendor/pharmacist. The leading reason why females felt that a health center was their preferred location for contraceptive service was its convenient location $(55 \%)$ while male youth felt health centers were the preferred location for condoms because of low-cost/free services $(53 \%)$. Female youth indicated that low-cost/free services $(32 \%)$ was also a reason and named this more often than friendly staff $(21 \%)$. Male youth on the other hand, said that providers at health centers kept their information confidential, which was a reason to go there.

The primary reason female youth reported that a hospital was their preferred location for contraceptive services was because all services are available at a hospital (51\%). For condoms, male youth said that drug vendors/pharmacists were their preferred source because of short waiting times $(32 \%)$, convenient hours $(30 \%)$, and convenient locations (22\%).

We asked respondents about their preferred type of provider for receiving contraceptive services or condoms. The interviewer read out all responses to this question and multiple responses were possible. The results of these data are presented in Table 25.

The preferred provider for contraceptive services or condoms was a provider at a health facility followed by HEWs and pharmacists for both female and male youth. Older respondents (18-24 year olds) were more likely to prefer a HEW who visits their house for contraceptive or condom services- $22 \%$ of females and $25 \%$ of males. The reason why HEWs were mentioned in this question and not in Table 24 may be because the responses were read out loud.

TABLE 24. PERCENTAGE DISTRIBUTION OF FEMALE AND

MALE RESPONDENTS REPORTING TOP 3 REASONS WHY YOUTH SELECTED PREFERRED LOCATION FOR SERVICES ${ }^{\dagger}$

\begin{tabular}{|c|c|c|}
\hline & Females & Males \\
\hline Health Center & $(n=1,131)$ & $(n=882)$ \\
\hline Located close to home, school, or work & 54.6 & 27.7 \\
\hline Low-cost or free service & 32.2 & 53.3 \\
\hline Friendly staff & 20.9 & - \\
\hline Provider keeps information confidential & - & 25.2 \\
\hline Health Post & $(n=300)$ & $(n=274)$ \\
\hline Located close to home, school, or work & 77.3 & 67.5 \\
\hline 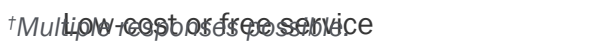 & 30.3 & 41.6 \\
\hline Friendly staff & 14.0 & 16.4 \\
\hline Hospital & $(n=168)$ & \\
\hline All services available in same facility & 50.6 & - \\
\hline Located close to home, school, or work & 18.5 & - \\
\hline Friendly staff & 17.3 & - \\
\hline Drug vendor/pharmacist & & $(n=125)$ \\
\hline Short waiting time & - & 32.0 \\
\hline Convenient hours & - & 30.4 \\
\hline Located close to home, school, or work & - & 22.4 \\
\hline
\end{tabular}


TABLE 25. PERCENT OF RESPONDENTS REPORTING PREFERRED PROVIDER FOR CONTRACEPTIVE (FEMALE) OR CONDOM (MALE) SERVICES BY AGE ${ }^{\dagger}$

\begin{tabular}{ccccccc}
\hline & $\begin{array}{c}\text { Physician, nurse, } \\
\text { midwife in health } \\
\text { facility }\end{array}$ & $\begin{array}{c}\text { HEW who } \\
\text { visits home }\end{array}$ & Pharmacist & Other & $\begin{array}{c}\text { No FP } \\
\text { knowledge }\end{array}$ & Total $\mathbf{n}$ \\
\hline Age & $* *$ & & Females & & & \\
$12-14$ & 72.5 & 19.4 & 3.8 & 0.4 & 14.6 & 494 \\
$15-17$ & 84.7 & 19.2 & 6.7 & 0.3 & 3.1 & 386 \\
$18-24$ & 86.0 & 24.5 & 5.3 & 0.4 & 0.7 & 943 \\
Total & 82.1 & 22.0 & 5.2 & 0.4 & 5.0 & 1,823 \\
\hline & & & Males & & & \\
\hline Age & $* *$ & $* *$ & $* *$ & & $* *$ & \\
$12-14$ & 58.5 & 23.9 & 13.4 & 4.6 & 14.5 & 544 \\
$15-17$ & 75.1 & 19.8 & 16.9 & 4.5 & 4.2 & 378 \\
$18-24$ & 76.9 & 28.1 & 19.6 & 4.6 & 0.5 & 866 \\
Total & 70.9 & 25.1 & 17.2 & 4.6 & 5.5 & 1,788 \\
\hline
\end{tabular}

${ }^{\dagger}$ Multiple responses possible.

${ }^{\star} p<0.05 ; * \star p<0.01$

Respondents were also asked their preferences for the sex and age of providers who offered contraceptive services or condoms. In Table 26, the majority of respondents prefer providers who are the same sex as them. For instance, among female youth $71 \%$ reported that they preferred a contraceptive provider who was close in age and of the same sex, and 60\% said they preferred a provider older and of the same sex. In contrast, only $32 \%$ of female youth said they preferred a provider who is close in age and of any sex or older and of any sex. A similar distribution is seen among male youth where most preferred a condom provider who is close in age and the same sex or older and the same sex.

TABLE 26. PERCENT OF RESPONDENTS REPORTING PREFERRED CONTRACEPTIVE (FEMALE)/CONDOM (MALE) PROVIDER CHARACTERISTICS

\begin{tabular}{ccccccc}
\hline & $\begin{array}{c}\text { Close to your } \\
\text { age and } \\
\text { same sex }\end{array}$ & $\begin{array}{c}\text { Close to your } \\
\text { age and any } \\
\text { sex }\end{array}$ & $\begin{array}{c}\text { Older and } \\
\text { same sex }\end{array}$ & $\begin{array}{c}\text { Older and } \\
\text { any sex }\end{array}$ & $\begin{array}{c}\text { No FP } \\
\text { knowledge }\end{array}$ & Total $\mathrm{n}$ \\
\hline Age & $* *$ & $* *$ & Females & $* *$ & $* *$ & $* *$ \\
$12-14$ & 62.8 & 25.3 & 51.2 & 24.9 & 14.6 & 494 \\
$15-17$ & 75.1 & 30.3 & 64.2 & 29.5 & 3.1 & 386 \\
$18-24$ & 73.0 & 36.9 & 60.9 & 37.1 & 0.7 & 943 \\
Total & 70.7 & 32.4 & 60.0 & 32.2 & 5.0 & 1,823 \\
\hline & & & Males & & & \\
\hline Age & $* *$ & $* *$ & $* *$ & $* *$ & $* *$ & \\
$12-14$ & 61.4 & 23.2 & 42.5 & 19.9 & 14.5 & 544 \\
$15-17$ & 66.7 & 24.3 & 52.6 & 25.1 & 4.2 & 378 \\
$18-24$ & 72.4 & 35.2 & 50.7 & 27.6 & 0.5 & 866 \\
Total & 67.8 & 29.3 & 48.6 & 24.7 & 5.5 & 1,788 \\
\hline
\end{tabular}

${ }^{\dagger}$ Multiple responses possible.

${ }^{\star} p<0.05 ; * \star p<0.01$ 


\section{ATTITUDES AROUND SEX, CONTRACEPTION, AND GENDER NORIS}

We asked all respondents attitudinal questions related to sex, pregnancy, contraceptive use, and communication and perceptions around gender norms. All of these questions were asked as statements on a 4-point Likert scale of strongly agree, agree, disagree, and strongly disagree. Strongly agree and agree were combined to form agreement with the statement and strongly disagree and disagree were combined to form disagreement with the statement. Figures 1, 2, and 3 present proportions of female and male youth who agreed with each statement.

Figure 1 shows young people's attitudes around sex and pregnancy. Females are more likely (79\%) to agree with the statement unmarried girls who have unplanned pregnancies are treated badly in my community. Females are also more likely $(85 \%)$ to be against premarital sex compared to males $(65 \%)$. A fairly close proportion of females and males agree with the statement that unmarried boys who get girls pregnant are blamed for the pregnancy. More males $(65 \%)$ than females $(36 \%)$, however, believe that abstaining from sex during adolescence is difficult.

\section{FIGURE 1. PERCENTAGE DISTRIBUTION OF FEMALE AND MALE RESPONDENTS' ATTITUDES AROUND SEX AND PREGNANCIES}

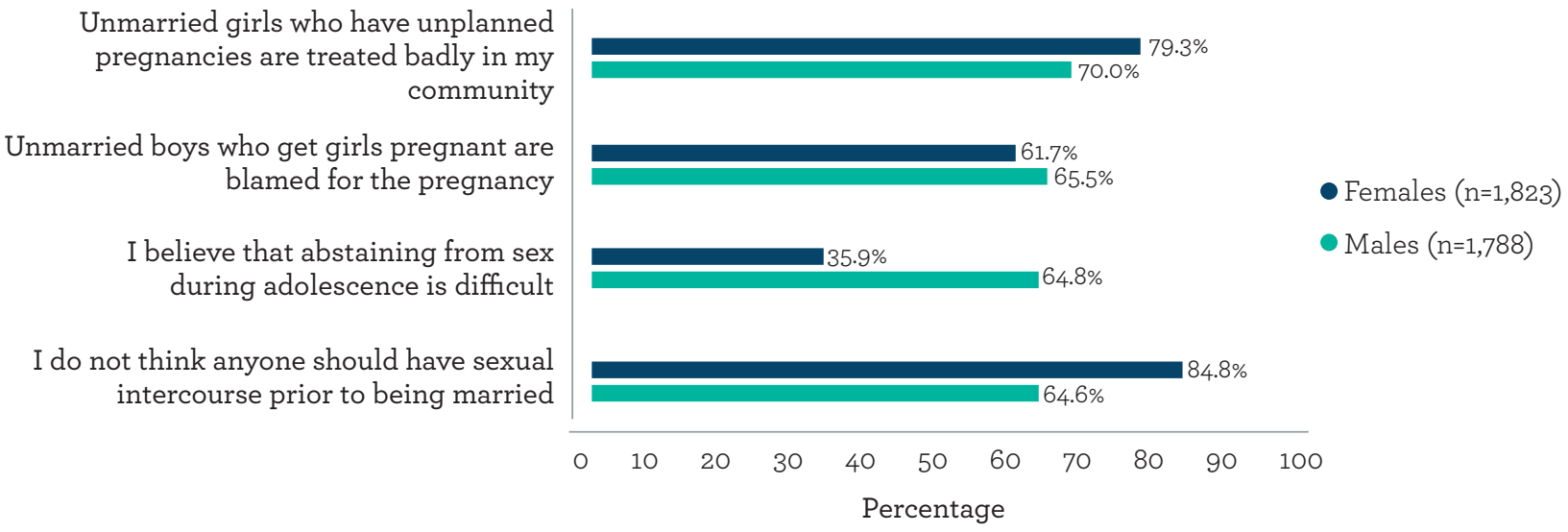

Figure 2 provides information on respondents' perceptions of contraceptive use. Overall, both females and males view unmarried girls' and boys' use of contraceptives or condoms negatively. Across all three statements, females are more likely to have negative attitudes toward the use of contraceptives among unmarried girls and boys. For example, $71 \%$ of females compared to $62 \%$ of males agree with the statement that unmarried girls who use contraception are considered promiscuous. When this statement was asked about boys' use of condoms and promiscuity, fewer females (66\%) and males $(58 \%)$ agreed with it. When asked whether boys/men should be the ones to decide if a couple uses family planning methods, one in four females agreed with this statement (25\%) while roughly one in five males $(19 \%)$ agreed.

Figure 3 presents respondents' attitudes around contraceptive communication. The majority of respondents, regardless of sex, agreed with the statements related to communication regarding contraception with health workers, parents, and friends. When respondents were asked: If I wanted to discuss contraception with my parents, they would be willing to discuss with me, a little more than half agreed with this statement even though more than 3 out of 4 female and male youth believed it was important to discuss contraception with their parents. Finally, roughly $16 \%$ of females and $34 \%$ of males have avoided/delayed seeking contraception and family planning services because they were afraid of what people would say about them. 


\section{FIGURE 2. PERCENTAGE DISTRIBUTION OF FEMALE AND MALE RESPONDENTS' ATTITUDES}

AROUND CONTRACEPTIVE USE

Unmarried girls who use contraception are considered promiscuous

Unmarried boys who use condoms are considered promiscuous

Unmarried girls who use contraception are said to be prostitutes in my community

Boys/men should be the ones to decide if a couple uses family planning methods

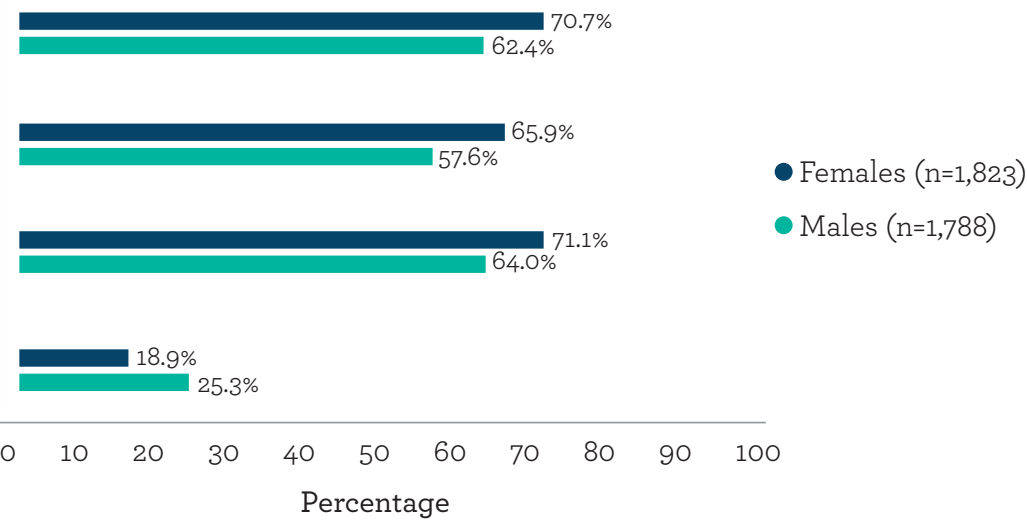

FIGURE 3. PERCENTAGE DISTRIBUTION OF FEMALE AND MALE RESPONDENTS' ATTITUDES AROUND CONTRACEPTIVE COMMUNICATION

I think it is important to discuss contraception with health workers

I think it is important to discuss contraception with my parents

I think it is important to discuss contraception with my friends

If I wanted to discuss contraception with my parents, they would be willing to discuss with me

I have avoided/delayed seeking contraception and family planning services because I was afraid of what people would say about me

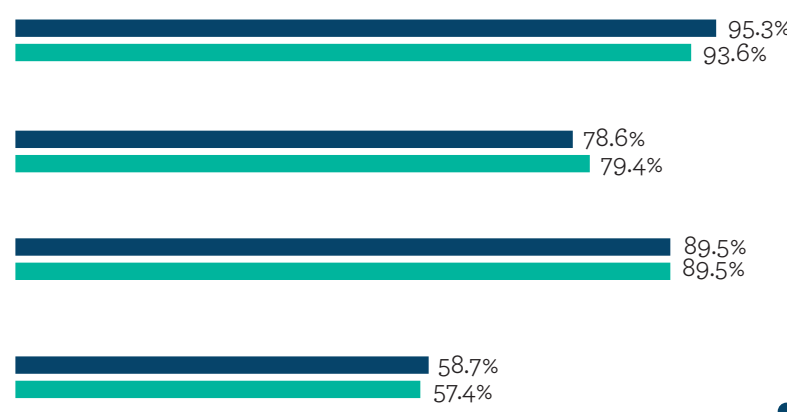

- Females ( $\mathrm{n}=1,823)$

- Males ( $\mathrm{n}=1,788)$
$16.1 \%$ $34.4 \%$

$\begin{array}{llllllllll}10 & 20 & 30 & 40 & 50 & 60 & 70 & 80 & 90 & 100\end{array}$

Percentage 


\section{CURRENT CONTRACEPTIVE USE}

We asked female respondents about their current contraceptive behaviors and excluded 12-14 year olds from these questions. Roughly $36 \%$ of sexually active 15-24 year old females reported using contraceptives (Table 27). More 18-24 year olds are using contraceptives compared to 15-17 year olds. Married females use contraceptive methods more so than either single or widowed/divorced/separated females. Amhara

\begin{tabular}{|c|c|c|}
\hline & \multicolumn{2}{|c|}{ Females } \\
\hline & $\%$ & Total $n$ \\
\hline \multicolumn{3}{|l|}{ Age } \\
\hline $15-17$ & 25.0 & 36 \\
\hline $18-24$ & 36.8 & 595 \\
\hline \multicolumn{3}{|l|}{ Marital Status } \\
\hline Single & 30.0 & 40 \\
\hline In union/married & 39.9 & 514 \\
\hline Widowed/divorced/separated & 14.3 & 77 \\
\hline \multicolumn{3}{|l|}{ Region } \\
\hline Tigray & 30.9 & 94 \\
\hline Amhara & 45.0 & 198 \\
\hline Oromia & 33.9 & 174 \\
\hline Benishangul-Gumuz & 32.4 & 68 \\
\hline SNNP & 29.9 & 97 \\
\hline Total & 36.1 & 631 \\
\hline
\end{tabular}

$12-14$ year olds are excluded from this analysis. ${ }^{\star} p<0.05 ; * \star p<0.01$

TABLE 28. PERCENT DISTRIBUTION OF SEXUALLY ACTIVE FEMALE RESPONDENTS REPORTING CURRENT METHOD USE ${ }^{\dagger}$

\begin{tabular}{lc}
\cline { 2 - 2 } & $\begin{array}{c}\text { Females } \\
(\mathrm{n}=6 \mathbf{6 3 1})^{+\dagger}\end{array}$ \\
\cline { 2 - 2 } & $\%$ \\
\hline FP Method & 0.3 \\
IUD/Loop & 23.8 \\
Injectables & 7.8 \\
Implant & 3.0 \\
Pill & 0.3 \\
Standard Days Method & 0.5 \\
Lactational Amenorrhea Method (LAM) & 0.6 \\
Rhythm Method & 0.2 \\
Withdrawal & 0.3 \\
Emergency Contraception & 63.9 \\
Not using FP method & \\
\hline
\end{tabular}

${ }^{\dagger}$ Multiple responses possible.

${ }^{+\dagger}$ Denominator excludes 12-24 year olds and those who have never had sex. region $(45 \%)$ appears to have the greatest proportion of users compared to other regions.

Table 28 shows the contraceptive methods that are currently being used. The percentages reported in this table also include females who are currently not using contraceptive methods. Twenty-four percent of sexually active female youth are using injectables, followed by implants $(8 \%)$ and pills (3\%). A little over $1 \%$ are using traditional methods and $0.3 \%$ are using the Standard Days Method.

\section{Future Intentions to Use Contraception}

Those who reported that they are currently not using a contraceptive method were asked their future intentions for using one. In Table 29, the majority of female youth reported that they intend to use a contraceptive method in the future $(81 \%)$. When asked which method they intended to use, most females reported the injectable $(60 \%)$, followed by the pill $(23 \%)$. (Note that this was a multiple response question so respondents could have reported more than one method.)

Less than 1 in 5 reported that they do not intend to use a contraceptive method in the future or did not know $(19 \%)$. Of those, most female youth reported wanting more children $(7 \%)$, followed by religious opposition (4\%) and not having sex $(3 \%)$ as the reasons for not intending to use contraception in the future. 
TABLE 29. FUTURE INTENTIONS TO USE CONTRACEPTION'

\begin{tabular}{|c|c|c|c|}
\hline & \multirow{2}{*}{\multicolumn{3}{|c|}{ Females }} \\
\hline & & & \\
\hline & $\begin{array}{c}15-17 \\
(n=373)\end{array}$ & $\begin{array}{c}18-24 \\
(n=721)\end{array}$ & $\begin{array}{c}\text { Total } \\
(n=1,094)\end{array}$ \\
\hline No/Don't know ${ }^{\dagger \dagger}$ & 16.6 & 19.6 & 18.6 \\
\hline \multicolumn{4}{|l|}{ Reason for not intending to use in the future: } \\
\hline Not having sex & 3.8 & 1.9 & 2.6 \\
\hline Infrequent sex & 0.3 & 0.1 & 0.2 \\
\hline Want more children & 5.6 & 8.2 & 7.3 \\
\hline Pregnant & 0.0 & 0.8 & 0.5 \\
\hline Respondent opposed & 0.3 & 0.7 & 0.5 \\
\hline Husband opposed & 0.3 & 0.8 & 0.6 \\
\hline Others opposed & 0.0 & 0.4 & 0.3 \\
\hline Religious prohibition & 2.7 & 4.9 & 4.1 \\
\hline Knows no method & 1.6 & 0.3 & 0.7 \\
\hline Knows no source & 0.3 & 0.1 & 0.2 \\
\hline Health concerns & 0.3 & 2.2 & 1.6 \\
\hline Fear of side effects & 1.9 & 2.1 & 2.0 \\
\hline Lack of access & 0.0 & 0.1 & 0.1 \\
\hline Inconvenient to use & 0.3 & 0.0 & 0.1 \\
\hline Causes infertility/sterility & 1.1 & 1.0 & 1.0 \\
\hline Other & 1.9 & 3.3 & 2.8 \\
\hline Don't know & 0.3 & 0.6 & 0.5 \\
\hline Yes & 83.4 & 79.9 & 81.1 \\
\hline \multicolumn{4}{|l|}{ Intended method: } \\
\hline Female sterilization & 1.1 & 0.7 & 0.8 \\
\hline Male sterilization & 0.0 & 0.3 & 0.2 \\
\hline IUD/Loop & 2.9 & 2.6 & 2.7 \\
\hline Injectables & 63.3 & 58.4 & 60.1 \\
\hline Implants & 12.6 & 15.4 & 14.4 \\
\hline Pill** & 29.5 & 19.0 & 22.6 \\
\hline Male condom & 1.9 & 1.4 & 1.6 \\
\hline Female condom & 0.0 & 0.7 & 0.5 \\
\hline Standard Days Method & 1.3 & 0.8 & 1.0 \\
\hline Lactational Amenorrhea Method (LAM) & 0.0 & 0.6 & 0.4 \\
\hline Rhythm method & 0.3 & 1.0 & 0.7 \\
\hline Withdrawal & 0.0 & 0.1 & 0.1 \\
\hline Emergency contraception & 0.0 & 0.1 & 0.1 \\
\hline Diaphragm & 0.3 & 0.1 & 0.2 \\
\hline Spermicide & 0.0 & 0.1 & 0.1 \\
\hline Other & 1.8 & 1.0 & 1.3 \\
\hline
\end{tabular}

${ }^{\dagger}$ Multiple responses possible.

${ }^{+}$Denominator excludes 12-24 year olds and those who have never had sex.

${ }^{\star} p<0.05 ; \star \star p<0.01$ 


\section{Ever Use of Contraception}

Table 30 presents the proportion of female respondents who have ever used a contraceptive method by age and region. Overall, close to 1 in $3(32 \%)$ youth have ever used a contraceptive method. Among 18-24 years olds, 42\% have used contraception compared to only 5\% among 15-17 year olds. Very few (4\%) currently single females have ever used contraception while more than half of married (66\%) females have ever used contraception. One in two (53\%) female youth living in Amhara have used contraception while only 16\% have in SNNP.

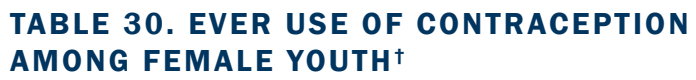

\begin{tabular}{lcc}
\cline { 2 - 3 } & \multicolumn{2}{c}{ Females } \\
\cline { 2 - 3 } & $\%$ & Total $\mathbf{~}$ \\
\hline Age** & 5.2 & 386 \\
$15-17$ & 42.3 & 943 \\
18-24 & & \\
Marital Status** & 4.1 & 734 \\
$\quad$ Single & 65.5 & 516 \\
$\quad$ In union/married & 64.6 & 79 \\
$\quad$ Widowed/divorced/separated & & \\
Region** & 26.3 & 259 \\
$\quad$ Tigray & 52.6 & 321 \\
$\quad$ Amhara & 27.1 & 325 \\
$\quad$ Oromia & 34.8 & 135 \\
$\quad$ Benishangul-Gumuz & 16.3 & 289 \\
$\quad$ SNNP & 31.5 & 1,329 \\
Total & & \\
\hline
\end{tabular}

${ }^{+}$Denominator excludes $12-14$ year olds.

${ }^{*} p<0.05 ;{ }^{*} p<0.01$

\section{TABLE 31. PERCENT OF SEXUALLY ACTIVE RESPONDENTS WHO HAVE EVER USED CONDOMS BY SELECT BACKGROUND CHARACTERISTICS ${ }^{\dagger}$} active male youth who reported that they have ever used condoms in their lifetime by age and region. About half of males have used condoms in their lifetime. Among 18-24 years olds, 48\% have used condoms. Among single male youth, only $66 \%$ have ever used condoms, while only $19 \%$ of married males have ever used condoms. Male youth living in Tigray are more likely to use condoms $(65 \%)$ than the other regions.

\begin{tabular}{lcc} 
& \multicolumn{2}{c}{ Males } \\
\cline { 2 - 3 } & $\%$ & Total $\mathrm{n}$ \\
\hline Age & 58.8 & 34 \\
$15-17$ & 48.3 & 387 \\
$18-24$ & & \\
Marital Status** & 66.2 & 260 \\
Single & 18.5 & 146 \\
In union/married & 50.0 & 14 \\
$\quad$ Widowed/divorced/separated & & \\
Region** & & \\
$\quad$ Tigray & 64.7 & 68 \\
$\quad$ Amhara & 28.0 & 75 \\
$\quad$ Oromia & 49.4 & 168 \\
Benishangul-Gumuz & 30.8 & 39 \\
$\quad$ SNNP & 66.2 & 71 \\
Total & 49.2 & 421 \\
\hline
\end{tabular}

${ }^{\dagger}$ Denominator excludes 12-14 year olds and those who have never had sex.

$\star p<0.05 ; * * p<0.01$ 
Table 32 shows condom use at last sex and reasons for using or not using condoms at last sex. Among male youth who have ever used a condom $(n=207), 73 \%$ reported using one at last sex. Their reasons for using condoms were to prevent pregnancy and prevent the transmission of STIs or HIV. The leading reason why male youth did not use a condom at last sex $(n=57)$ was that they were in a stable relationship.

\begin{tabular}{|c|c|c|}
\hline & \multicolumn{2}{|c|}{ Males } \\
\hline & $\%$ & Total $n$ \\
\hline Condom use at last sex & 72.5 & 207 \\
\hline Reasons for using condoms ${ }^{\dagger}$ & - & 150 \\
\hline Prevention of pregnancy & 81.3 & - \\
\hline Prevention of STIS/HIV & 83.3 & - \\
\hline Partner's request & 8.0 & - \\
\hline Reasons for not using condoms ${ }^{\dagger}$ & - & 57 \\
\hline In a stable partnership & 71.9 & - \\
\hline Want children & 17.5 & - \\
\hline Partner opposed to contraception & 5.3 & - \\
\hline Religious prohibition & 1.8 & - \\
\hline Condoms interrupt the moment & 3.5 & - \\
\hline Condoms decrease sexual pleasure & 7.0 & - \\
\hline
\end{tabular}

${ }^{\dagger}$ Multiple responses possible

\section{USE OF YFS AND NON-YFS SITES FOR HEALTH SERVICES IN THE PAST SIX MONTHS (FEMALES)}

We asked female respondents aged 15-24 years if they had visited a health facility for contraceptive, maternal health, or basic services within 6 months preceding the survey. Fourteen percent of respondents had gone for contraceptive services; $9 \%$ for maternal health services; and 24\% for basic health services (data not shown). Some respondents obtained more than one service during this time period; thus $39 \%$ of respondents had been to a facility for services.

Respondents were also asked to name the facility that they visited in the past 6 months for these services. Based on the responses, we matched the sites reported by respondents to the list of YFS sites that was gathered from the regional health bureaus. Table 33 shows the proportion of health service used among respondents who reported using health services in the past 6 months by YFS site. In the 6 months preceding the survey, $33 \%$ of respondents seeking contraceptive services went to a YFS site, $39 \%$ of maternal health users went to a YFS site, and 29\% of basic health service users went to a YFS site.

TABLE 33. PERCENTAGE DISTRIBUTION OF FEMALES WHO VISITED A YFS/NON-YFS SITE WITHIN THE PAST 6 MONTHS OF THE SURVEY, BY SERVICE TYPE ${ }^{\dagger}$

\begin{tabular}{lccc}
\hline Service type & YFS & Non-YFS & Total $\mathbf{n}$ \\
\hline Family Planning (FP) & 32.6 & 67.4 & 187 \\
Maternal Health (MH) & 38.7 & 61.3 & 119 \\
Basic Health (BH) & 29.1 & 70.9 & 320 \\
\hline
\end{tabular}

${ }^{\dagger}$ Multiple responses possible 
The data presented in Table 34 are limited to females who lived close to a YFS site (i.e. less than 10 kilometers from a YFS site) and show the proportion of that group that went to a YFS or non-YFS site for different services. For family planning services, $43 \%$ went to a YFS site; $47 \%$ went to a YFS site for maternal health services; and 37\% went to a YFS site for basic health services. These data suggest that though many female respondents prefer to go to a non-YFS site, they are more likely to visit YFS sites for specialized services than for basic services.

The following data tables present results for use of FP, maternal health, or basic health services at a YFS versus non-YFS site within the past 6 months. Table 35 shows the use of a health service by demographiccharacteristics. The majority of users irrespective of service type are older females. For FP and maternal health services the majority of users are married, but for basic health services there is an equal proportion of single and married users as would be expected. Most users of FP and maternal health services have at least one child, whereas females without any children are mainly the users of basic health services.

TABLE 35. PERCENTAGE DISTRIBUTION OF FEMALE USERS OF FAMILY PLANNING, MATERNAL HEALTH, OR BASIC HEALTH SERVICES BY SELECT CHARACTERISTICS, ACCORDING TO TYPE OF SITE VISITED

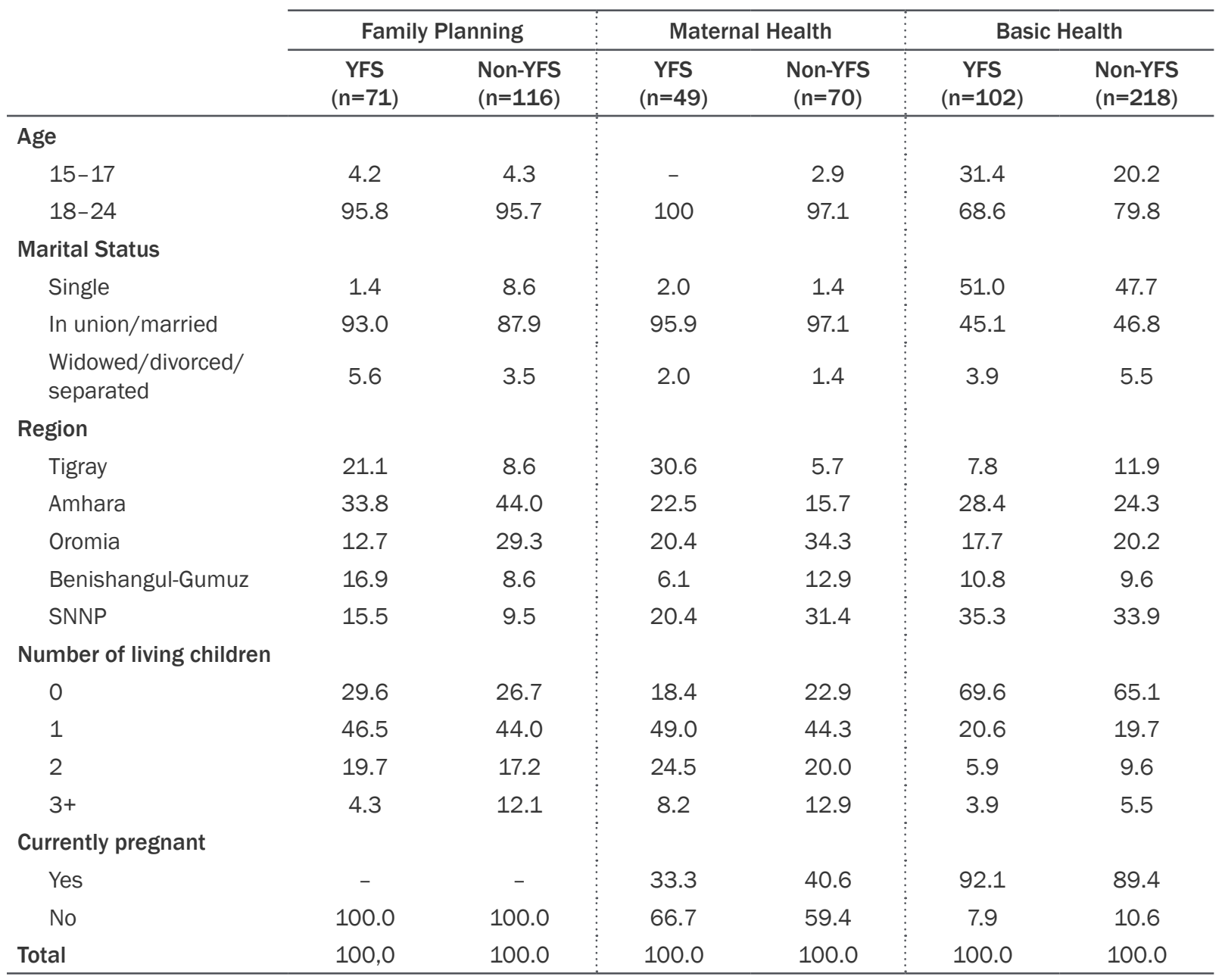

TABLE 34. PERCENTAGE DISTRIBUTION OF FEMALE USERS OF YFS SERVICES FOR FAMILY PLANNING, MATERNAL HEALTH, OR BASIC HEALTH, AMONG THOSE WHO LIVE NEAR A YFS SITE

\begin{tabular}{|c|c|c|c|}
\hline & $\begin{array}{l}\text { Family Planning } \\
\qquad(n=162)\end{array}$ & $\begin{array}{l}\text { Maternal Health } \\
\qquad(n=98)\end{array}$ & $\begin{array}{l}\text { Basic Health } \\
\quad(n=267)\end{array}$ \\
\hline YFS & 42.6 & 46.9 & 36.7 \\
\hline Non-YFS & 57.4 & 53.1 & 63.3 \\
\hline
\end{tabular}


Table 36 shows the reasons for FP and maternal health visits. A little more than half of the visitors to a YFS site and non-YFS site went for contraceptive re-supply, followed by method start. For maternal care services, about 2 in 5 respondents went for prenatal care, followed by labor and delivery.

\begin{tabular}{lcc} 
TABLE 36. PERCENTAGE DISTRIBUTION OF FEM LLES \\
WHO VISITED A YFS N N N-YFS SITE BY REASON FOR \\
FAMILY PLAN N ING AN D M ATER N AL HEALTH VISIT \\
\cline { 2 - 3 } & $\begin{array}{c}\text { YFS } \\
(\mathbf{n}=71)\end{array}$ & $\begin{array}{c}\text { Non-YFS } \\
(\mathbf{n}=116)\end{array}$ \\
\hline Family Planning & & \\
Initial consultation & 2.8 & 1.7 \\
Contraceptive re-supply & 56.3 & 57.8 \\
Method counseling/ & 1.4 & 5.1 \\
discuss side effects & 32.4 & 25.0 \\
Method start & 4.2 & 6.0 \\
Method switching & 1.4 & - \\
Method removal & 1.4 & 4.3 \\
Other & & \\
& YFS & Non-YFS \\
Maternal Health & $(\mathbf{n}=70)$ \\
Prenatal care & 61.2 & 60.0 \\
Postnatal care & 18.4 & 12.9 \\
Labor and delivery & 20.4 & 20.0 \\
Other & - & 7.1 \\
Total & 100.0 & 100.0 \\
\hline
\end{tabular}

Table 37 shows the outcome of the FP visit. Across both YFS and non-YFS sites, most respondents left with the method that they requested, which was the injectable contraceptive method.

\begin{tabular}{|c|c|c|}
\hline & $\begin{array}{c}\text { YFS } \\
(n=71)\end{array}$ & $\begin{array}{l}\text { Non-YFS } \\
(n=116)\end{array}$ \\
\hline \multicolumn{3}{|l|}{ Outcome of Family Planning Visit: ${ }^{\dagger}$} \\
\hline Left with requested method & 90.1 & 90.5 \\
\hline Left with different method & 8.5 & 5.2 \\
\hline Left with no method & 1.4 & 3.5 \\
\hline \multicolumn{3}{|l|}{ Method received: ${ }^{\dagger \dagger}$} \\
\hline Injectables & 74.7 & 80.2 \\
\hline Implants & 11.3 & 6.9 \\
\hline Pills & 14.1 & 6.9 \\
\hline Emergency Contraception & - & 1.7 \\
\hline
\end{tabular}

+ Column percentages may not add to $100 \%$ due to missing values.

${ }^{+t}$ Multiple responses possible. 


\section{Physical Access to Health Facility}

Respondents were asked the mode of transportation used to reach the place they last went to for FP, maternal health, and basic health services. For female youth who went to YFS and non-YFS facilities for all service types, many more traveled by foot than by taxi/bajaj or bus (Table 38). Among those who reported that they had traveled by foot, we asked how long it took to get to the health facility. On average, it took more time for youth to travel to YFS sites compared to non-YFS sites for all three service types (45 minutes vs 27 minutes for FP; 36 minutes vs 27 minutes for $\mathrm{MH}$; and 55 minutes vs 42 minutes for $\mathrm{BH}$ ). This suggests that YFS services are a great distance from the users and those who have used YFS services are willing to travel a long distance to access them.

TABLE 38. PERCENTAGE DISTRIBUTION OF FEMALE USERS OF FAMILY PLANNING, MATERNAL HEALTH, OR BASIC HEALTH SERVICES BY MODE OF TRANSPORTATION, ACCORDING TO TYPE OF SITE VISITED

\begin{tabular}{|c|c|c|c|c|c|c|}
\hline & \multirow{2}{*}{\multicolumn{2}{|c|}{ Family Planning }} & & & & \\
\hline & & & \multicolumn{2}{|c|}{ Maternal Health } & \multicolumn{2}{|c|}{ Basic Health } \\
\hline & $\begin{array}{c}\text { YFS } \\
(n=71)\end{array}$ & $\begin{array}{l}\text { Non-YFS } \\
(n=116)\end{array}$ & $\begin{array}{c}\text { YFS } \\
(n=49)\end{array}$ & $\begin{array}{c}\text { Non-YFS } \\
(n=70)\end{array}$ & $\begin{array}{c}\text { YFS } \\
(n=102)\end{array}$ & $\begin{array}{l}\text { Non-YFS } \\
(n=218)\end{array}$ \\
\hline \multicolumn{7}{|l|}{ Mode of transportation ${ }^{\dagger \dagger}$} \\
\hline Taxi/bajaj & 29.6 & 15.5 & 44.9 & 25.7 & 36.3 & 27.5 \\
\hline Bus & 7.0 & 0.9 & 8.2 & 2.9 & 16.7 & 12.8 \\
\hline Motorbike & 1.4 & - & - & 1.4 & 6.9 & 7.8 \\
\hline Bicycle & - & - & - & - & - & 0.5 \\
\hline Cart & 2.8 & 3.5 & 2.0 & 5.7 & 1.9 & 5.5 \\
\hline Animal back (horse, mule, donkey) & - & - & 2.0 & - & 1.0 & 0.5 \\
\hline By foot & 70.4 & 85.3 & 61.2 & 68.1 & 64.7 & 64.7 \\
\hline By foot: Time to travel to health facility ${ }^{\dagger \dagger}$ & $(n=50)$ & $(n=99)$ & $(n=30)$ & $(n=47)$ & $(n=66)$ & $(n=141)$ \\
\hline$<10$ minutes & 16.0 & 22.2 & 16.7 & 23.4 & 9.1 & 12.8 \\
\hline 10 to $<30$ minutes & 32.0 & 42.4 & 33.3 & 31.9 & 28.8 & 30.5 \\
\hline 3- to $<60$ minutes & 10.0 & 16.2 & 20.0 & 27.7 & 21.2 & 27.0 \\
\hline 60 to 315 minutes & 42.0 & 18.2 & 30.0 & 14.9 & 40.9 & 29.8 \\
\hline Mean & 45.3 & 26.7 & 36.3 & 27.3 & 54.9 & 41.6 \\
\hline Median & 30.0 & 15.0 & 27.5 & 20.0 & 35.0 & 30.0 \\
\hline
\end{tabular}

${ }^{+}$Column percentages may not add to $100 \%$ due to missing values.

${ }^{+}$Multiple responses possible.

\section{Aspects of Quality}

Respondents were asked about different aspects of the quality of care they received at the most recent visit for family planning, maternal health, and basic health services. Table 39 shows the length of time respondents waited to be seen. Across all health visit types, fewer youth were seen immediately at a YFS site compared to a non-YFS site. On average, youth who attended a YFS facility compared to a non-YFS facility for family planning service were seen 13 minutes later and 9 minutes later for basic health services. These waiting times should be considered in the context of high client load and longer consultations, both of which may also demonstrate aspects of good quality but were not captured in this current study. Youth were seen 2 minutes sooner if they went for maternal health services at a YFS site.

Table 40 shows levels of satisfaction with services received and quality of services rendered by a provider. There are no differences among respondents who went to a YFS site compared to a non-YFS site on these aspects of quality or across the health service obtained. Overall the majority of respondents reported that they were satisfied with family planning, maternal health, or basic health services received irrespective of whether they went to a YFS or non-YFS site. Most also felt that they were treated well, felt comfortable asking questions, felt that the provider was knowledgeable about contraceptives, and felt confident that 
their information would remain confidential. There were no differences in these indicators by YFS or nonYFS facility. For family planning services, few respondents overall reported that the provider mentioned the side effects associated with the method selected.

TABLE 39. PERCENTAGE DISTRIBUTION OF FEMALE USERS OF FAMILY PLANNING MATERNAL HEALTH OR BASIC HEALTH SERVICES BY WAITING TIME, ACCORDING TO TYPE OF SITE VISITED ${ }^{\dagger}$

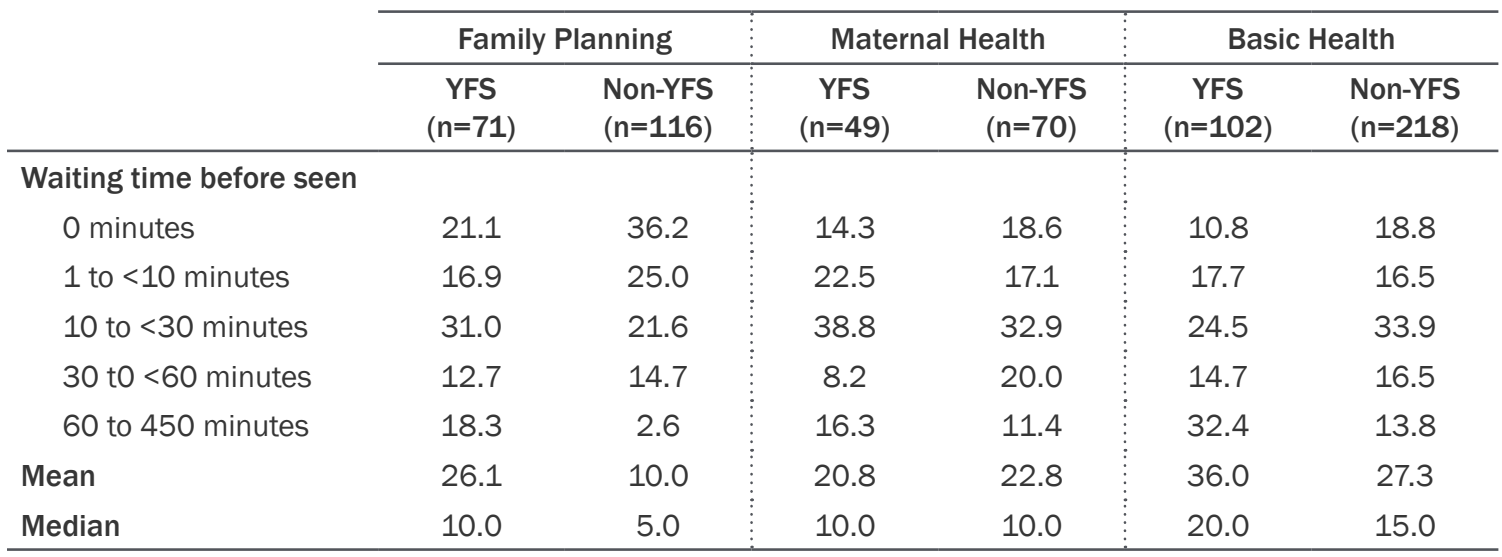

${ }^{+}$Column percentages may not add to $100 \%$ due to missing values.

${ }^{+}$Multiple responses possible.

TABLE 40. PERCENTAGE DISTRIBUTION OF FEMALE USERS OF FAMILY PLANNING, MATERNAL HEALTH, OR BASIC HEALTH SERVICES BY ASPECTS OF QUALITY, ACCORDING TO TYPE OF SITE VISITED

\begin{tabular}{|c|c|c|c|c|c|c|}
\hline & \multicolumn{2}{|c|}{ Family Planning } & \multicolumn{2}{|c|}{ Maternal Health } & \multicolumn{2}{|c|}{ Basic Health } \\
\hline & $\begin{array}{c}\text { YFS } \\
(n=71)\end{array}$ & $\begin{array}{l}\text { Non-YFS } \\
(n=116)\end{array}$ & $\begin{array}{c}\text { YFS } \\
(n=49)\end{array}$ & $\begin{array}{c}\text { Non-YFS } \\
(n=70)\end{array}$ & $\begin{array}{c}\text { YFS } \\
(n=102)\end{array}$ & $\begin{array}{l}\text { Non-YFS } \\
(n=218)\end{array}$ \\
\hline Satisfied with visit at facility & 95.8 & 97.4 & 93.9 & 88.7 & 95.1 & 94.0 \\
\hline Among those who saw a provider at the visit: & $(n=65)$ & $(n=114)$ & $(n=49)$ & $(n=69)$ & $(n=98)$ & $(n=210)$ \\
\hline Mentioned side effects of method received & 41.5 & 36.8 & - & - & - & - \\
\hline Treated well & 98.5 & 99.1 & 100.0 & 95.7 & 96.9 & 100.0 \\
\hline Felt comfortable asking questions & 96.9 & 98.3 & 95.9 & 89.9 & 95.9 & 97.1 \\
\hline Provider was knowledgeable & 100.0 & 99.1 & 95.9 & 91.3 & 98.0 & 98.6 \\
\hline Felt information would be kept confidential & 89.2 & 92.1 & 93.9 & 85.5 & 95.9 & 93.8 \\
\hline $\begin{array}{l}\text { Agreed with the statement: "The way that } \\
\text { the provider spoke to me made me feel bad } \\
\text { about myself." }\end{array}$ & 6.2 & 4.4 & 10.2 & 17.4 & 7.1 & 6.7 \\
\hline
\end{tabular}




\section{Cost of Services Received}

We also asked respondents how much money they paid for their visit (Table 41). Among respondents who went to a YFS site for family planning, $92 \%$ received services for free compared to only $65 \%$ at a non-YFS facility. For maternal health services, $94 \%$ received services for free at YFS sites compared to $87 \%$ at nonYFS sites. For basic health services, the majority of respondents had to pay more than 10 Ethiopian birr (equivalent to US\$0.50) for their visit.

TABLE 41. PERCENTAGE DISTRIBUTION OF FEMALE USERS OF FAMILY PLANNING, MATERNAL HEALTH, OR BASIC HEALTH SERVICES BY COST OF SERVICE RECEIVED, ACCORDING TO TYPE OF SITE VISITED ${ }^{\dagger}$

\begin{tabular}{lcc|cc|cc} 
& \multicolumn{2}{c}{ Family Planning } & \multicolumn{2}{c}{ Maternal Health } & \multicolumn{2}{c}{ Basic Health } \\
\cline { 2 - 7 } & $\begin{array}{c}\text { YFS } \\
(\mathbf{n}=72)\end{array}$ & $\begin{array}{c}\text { Non-YFS } \\
(\mathbf{n}=115)\end{array}$ & $\begin{array}{c}\text { YFS } \\
(\mathrm{n}=49)\end{array}$ & $\begin{array}{c}\text { Non-YFS } \\
(\mathbf{n}=70)\end{array}$ & $\begin{array}{c}\text { YFS } \\
(\mathbf{n}=102)\end{array}$ & $\begin{array}{c}\text { Non-YFS } \\
(\mathbf{n}=\mathbf{2 1 8})\end{array}$ \\
\hline Free & 91.6 & 64.7 & 93.9 & 87.1 & 6.9 & 4.6 \\
<10 Ethiopian birr & 1.4 & 10.3 & 4.1 & - & - & 0.5 \\
10 Ethiopian birr & 5.6 & 18.1 & - & 1.4 & 1.0 & - \\
>10 Ethiopian birr & 1.4 & 5.2 & 2.0 & 11.4 & 91.2 & 92.1 \\
\hline
\end{tabular}

+ Column percentages may not add to $100 \%$ due to missing values.

Among those who paid for family planning services, the majority felt the cost was affordable. For maternal health, about 1 in 3 respondents who paid for services at a non-YFS sites said it was unaffordable. Similarly for basic health, 33\% of respondents who went to a YFS site and $40 \%$ who went to a non-YFS site said the cost was unaffordable (Table 42).

TABLE 42. PERCENTAGE DISTRIBUTION OF FEMALE USERS OF FAMILY PLANNING, MATERNAL HEALTH, OR BASIC HEALTH SERVICES BY AFFORDABILITY OF SERVICE RECEIVED, ACCORDING TO TYPE OF SITE VISITED

\begin{tabular}{lcc:cc|cc} 
& \multicolumn{2}{c}{ Family Planning } & \multicolumn{2}{c}{ Maternal Health } & \multicolumn{2}{c}{ Basic Health } \\
\cline { 2 - 8 } & $\begin{array}{c}\text { YFS } \\
(\mathrm{n}=10)\end{array}$ & $\begin{array}{c}\text { Non-YFS } \\
(\mathrm{n}=\mathbf{3 9})\end{array}$ & $\begin{array}{c}\text { YFS } \\
(\mathrm{n}=5)\end{array}$ & $\begin{array}{c}\text { Non-YFS } \\
(\mathrm{n}=13)\end{array}$ & $\begin{array}{c}\text { YFS } \\
(\mathrm{n}=95)\end{array}$ & $\begin{array}{c}\text { Non-YFS } \\
(\mathrm{n}=\mathbf{2 0 8})\end{array}$ \\
\hline Affordable & 90.0 & 87.2 & 100.0 & 69.2 & 67.4 & 59.6 \\
Not affordable & 10.0 & 12.8 & - & 30.8 & 32.6 & 40.4 \\
Total & 100.0 & 100.0 & 100.0 & 100.0 & 100.0 & 100.0 \\
\hline
\end{tabular}




\section{USE OF YFS AND NON-YFS SITES FOR HEALTH SERVICES IN THE PAST SIX MONTHS (MALES)}

We asked male respondents aged 15-24 years old if they had visited a health facility for HIV testing, counseling, or treatment or for basic services within 6 months preceding the survey. Overall, $8 \%$ of respondents went to a facility for one or more of these services: $2 \%$ for HIV services and $6 \%$ for basic health services (data not shown).

Respondents were asked to name the facility they visited in the past 6 months for these services. Based on the responses, we matched the sites reported by respondents to the list of YFS sites that was gathered from the regional health bureaus. Among males who reported using HIV services, $35 \%$ went to a YFS site, while 21\% went to a YFS site for basic services (Table 43).

The majority of respondents who visited a YFS facility for HIV services or basic services lived within $10 \mathrm{~km}$ of the facility (96\% for HIV services and 100\% for basic services) (data not shown). However, among those who visited a non-YFS site, most also lived within $10 \mathrm{~km}$ away from a YFS site (67\% for HIV services and $72 \%$ for basic services) suggesting that they may have chosen not to go to a facility that was close in proximity to them. We do not know the reason why these respondents chose not to go to a YFS site for services.

The data presented in Table 44 are limited to males who live close to a YFS site (i.e. less than 10 kilometers from a YFS site). Among this group, 45\% went to a YFS site for HIV services while $28 \%$ went to a YFS site for basic health services. This suggests that male youth who live near to a YFS site prefer to go to non-YFS sites for basic health services but may be more inclined to use YFS sites for specialized services.

The following data tables (Table 45 and Table 46) present results for use of HIV service and basic health services received from a YFS versus non-YFS site within the past 6 months. The majority of males who used HIV services were older and single irrespective of where they received the services. By region, however, 1 in 4 used YFS services in Tigray, Amhara, and
TABLE 43. PERCENTAGE DISTRIBUTION OF MALES WHO VISITED A YFS/NON-YFS SITE WITHIN THE PAST 6 MONTHS OF THE SURVEY, BY SERVICE TYPE'

\begin{tabular}{lccc}
\hline Service Type & YFS & Non-YFS & Total $\mathbf{n}$ \\
\hline HIV & 34.5 & 65.5 & 84 \\
Basic & 20.9 & 78.2 & 316 \\
\hline
\end{tabular}

${ }^{\dagger}$ Multiple responses possible.

TABLE 44. PERCENTAGE DISTRIBUTION OF MALE USERS OF YFS SERVICES FOR FAMILY PLANNING, MATERNAL HEALTH, OR BASIC HEALTH, AMONG THOSE WHO LIVE NEAR A YFS SITE

\begin{tabular}{lc:c}
\cline { 2 - 3 } & $\begin{array}{c}\text { HIV Health } \\
(\mathrm{n}=65)\end{array}$ & $\begin{array}{c}\text { Basic Health } \\
(\mathrm{n}=\mathbf{2 4 4})\end{array}$ \\
\cline { 2 - 4 } YFS & 44.6 & 28.3 \\
Non-YFS & 55.4 & 71.7 \\
\hline
\end{tabular}

TABLE 45. PERCENTAGE DISTRIBUTION OF MALE USERS OF HIV OR BASIC HEALTH SERVICES BY SELECT CHARACTERISTICS, ACCORDING TO TYPE OF SITE VISITED

\begin{tabular}{cc|cc}
\hline HIV Health & \multicolumn{2}{c}{ Basic Health } \\
\hline YFS & Non-YFS & YFS & Non-YFS \\
$(n=30)$ & $(n=54)$ & $(n=69)$ & $(n=243)$ \\
\hline
\end{tabular}

\begin{tabular}{|c|c|c|c|c|}
\hline \multicolumn{5}{|l|}{ Age } \\
\hline $15-17$ & 16.7 & 12.0 & 29.0 & 27.6 \\
\hline $18-24$ & 83.3 & 87.0 & 71.0 & 72.4 \\
\hline \multicolumn{5}{|l|}{ Marital Status } \\
\hline Single & 83.3 & 70.4 & 88.4 & 86.0 \\
\hline In union/married & 13.3 & 27.8 & 8.7 & 12.8 \\
\hline $\begin{array}{l}\text { Widowed/divorced/ } \\
\text { separated }\end{array}$ & 3.3 & 1.9 & 2.9 & 0.8 \\
\hline \multicolumn{5}{|l|}{ Region } \\
\hline Tigray & 23.3 & 13.0 & 13.0 & 11.9 \\
\hline Amhara & 26.7 & 24.1 & 29.0 & 28.0 \\
\hline Oromia & 6.7 & 35.2 & 24.6 & 19.3 \\
\hline $\begin{array}{l}\text { Benishangul- } \\
\text { Gumuz }\end{array}$ & 16.7 & 11.1 & 8.7 & 10.3 \\
\hline SNNP & 26.7 & 16.7 & 24.7 & 30.5 \\
\hline Total & 100.0 & 100.0 & 100.0 & 100.0 \\
\hline
\end{tabular}


SNNP, whereas $24 \%$ and $35 \%$ used nonYFS HIV services in Amhara and Oromia. In terms of basic health services, younger males used this service more compared to HIV services. Similar distributions to HIV services are seen for marital status and region for basic services.

\section{TABLE 46. PERCENTAGE DISTRIBUTION OF MALES WHO VISITED A YFS/NON-YFS SITE BY REASON FOR HIV VISIT ${ }^{\dagger}$}

\begin{tabular}{lcc}
\hline Reason for HIV visit & $\begin{array}{c}\text { YFS } \\
(\mathrm{n}=30)\end{array}$ & $\begin{array}{c}\text { Non-YFS } \\
(\mathrm{n}=54)\end{array}$ \\
\hline Testing & 90.0 & 85.2 \\
Counseling & 10.0 & 1.9 \\
Treatment & - & 3.7 \\
Other & - & 5.6 \\
\hline
\end{tabular}

+ Column percentages may not add to $100 \%$ due to missing values.

\section{Physical Access to Health Facility}

Table 47 shows the mode of transportation taken by male users of HIV or basic health services, by type of site visited. The majority of male respondents reported that they traveled by foot to a health facility in the 6 months preceding the survey regardless of service type or facility type. Among those who traveled by foot, the average time to reach a YFS site for HIV services was 54 minutes and 45 minutes for basic health services. To reach a non-YFS site, the average times were slightly lower at 33 minutes for HIV services and 39 minutes for basic health services.

TABLE 47. PERCENTAGE DISTRIBUTION OF MALE USERS OF HIV SERVICES OR BASIC HEALTH SERVICES REPORTING MODE OF TRANSPORTATION, BY TYPE OF SITE VISITED

\begin{tabular}{|c|c|c|c|c|}
\hline & \multirow{2}{*}{\multicolumn{2}{|c|}{ HIV Health }} & & \\
\hline & & & \multicolumn{2}{|c|}{ Basic Health } \\
\hline & $\begin{array}{c}\text { YFS } \\
(n=30)\end{array}$ & $\begin{array}{c}\text { Non-YFS } \\
(n=54)\end{array}$ & $\begin{array}{c}\text { YFS } \\
(n=69)\end{array}$ & $\begin{array}{l}\text { Non-YFS } \\
(n=243)\end{array}$ \\
\hline \multicolumn{5}{|l|}{ Mode of transportation ${ }^{\dagger}$} \\
\hline Taxi/bajaj & 30.0 & 18.5 & 37.7 & 18.1 \\
\hline Bus & 3.3 & 11.1 & 5.8 & 7.4 \\
\hline Motorbike & 3.3 & - & - & 6.6 \\
\hline Bicycle & 3.3 & - & - & - \\
\hline Cart & 3.3 & 7.4 & 1.5 & 5.4 \\
\hline Animal back (horse, mule, donkey) & 3.3 & 1.9 & 2.9 & 0.8 \\
\hline By foot & 80.0 & 79.6 & 72.5 & 77.0 \\
\hline By foot: Time to travel to health facility & $(n=24)$ & $(n=44)$ & $(n=53)$ & $(n=192)$ \\
\hline$<10$ minutes & 8.3 & 20.5 & 1.9 & 11.5 \\
\hline 10 to $<30$ minutes & 20.8 & 38.6 & 35.9 & 34.9 \\
\hline 3- to $<60$ minutes & 33.3 & 22.7 & 28.3 & 28.7 \\
\hline 60 to 315 minutes & 37.5 & 18.2 & 34.0 & 25.0 \\
\hline Mean & 53.7 & 32.6 & 44.5 & 38.7 \\
\hline Median & 30.0 & 20.0 & 30.0 & 30.0 \\
\hline
\end{tabular}

${ }^{\dagger}$ Multiple responses possible. 


\section{Aspects of Quality}

The amount of time a male user of HIV or basic health services waited before being seen at a YFS or non-YFS facility is shown in Table 48. On average, for HIV services males waited close to 12 minutes less at YFS compared to non-YFS sites. For basic health services, however, males waited more than 5 minutes more at YFS versus non-YFS sites.

Table 49 presents respondents' perceptions of receiving quality services at YFS and non-YFS facilities. There is no difference between the quality of services received from a YFS site and a non-YFS site for HIV and basic health services. The overwhelming majority of respondents were satisfied with the HIV services or basic health services they received regardless of where they went to obtain them. The majority of respondents also reported that they felt like they were treated well by a provider, felt comfortable asking questions, felt the provider was knowledgeable, and felt confident that their information would be kept confidential. This was true among respondents who went to YFS and non-YFS facilities.

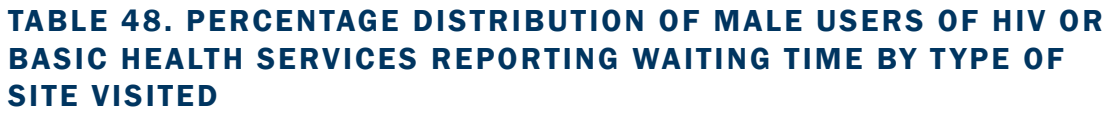

\begin{tabular}{|c|c|c|c|c|}
\hline & \multirow{2}{*}{\multicolumn{2}{|c|}{ HIV Health }} & & \\
\hline & & & \multicolumn{2}{|c|}{ Basic Health } \\
\hline & $\begin{array}{c}\text { YFS } \\
(n=30)\end{array}$ & $\begin{array}{c}\text { Non-YFS } \\
(n=54)\end{array}$ & $\begin{array}{c}\text { YFS } \\
(n=69)\end{array}$ & $\begin{array}{l}\text { Non-YFS } \\
(n=243)\end{array}$ \\
\hline \multicolumn{5}{|c|}{ Waiting time before seen ${ }^{\dagger}$} \\
\hline 0 minutes & 10.0 & 7.4 & 4.4 & 12.4 \\
\hline 1 to 10 minutes & 23.3 & 14.8 & 13.0 & 15.2 \\
\hline 10 to $<30$ minutes & 43.3 & 31.5 & 30.4 & 35.8 \\
\hline 30 to $<60$ minutes & 16.7 & 33.3 & 34.8 & 19.8 \\
\hline 60 to 390 minutes & 6.7 & 11.1 & 15.9 & 15.6 \\
\hline Mean & 16.3 & 28.1 & 33.9 & 27.1 \\
\hline Median & 13.5 & 20.0 & 30.0 & 15.0 \\
\hline
\end{tabular}

${ }^{\dagger}$ Column percentages may not add to $100 \%$ due to missing values.

TABLE 49. PERCENT OF RESPONDENTS REPORTING SATISFACTION WITH SERVICES RECEIVED AND QUALITY OF SERVICES OFFERED BY PROVIDER, BY TYPE OF SITE VISITED

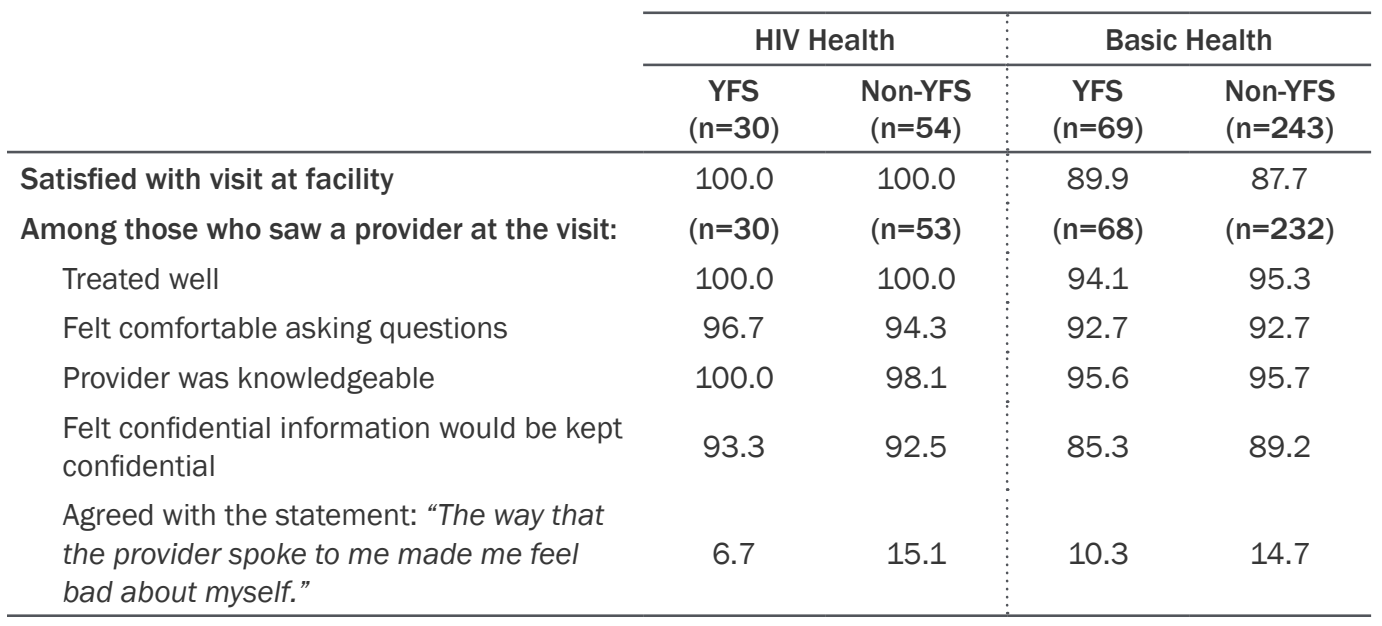




\section{Cost of Services Received}

Tables 50 and 51 show the cost of services received and whether respondents felt like these costs were affordable. The cost of HIV services appears to be less expensive at YFS sites compared to non-YFS sites. At YFS sites, $80 \%$ of respondents reported receiving free services compared to $69 \%$ at non-YFS sites. For basic health services, regardless of whether a respondent went to a YFS or non-YFS site, more than $86 \%$ of respondents reported having to pay more than 10 birr. A little less than half of respondents (43\%) who went to a non-YFS site reported that costs were not affordable for basic health services and 25\% reported this for YFS sites (Table 51).

\section{TABLE 50. PERCENT OF RESPONDENTS REPORTING COST OF HIV AND BASIC HEALTH SERVICES RECEIVED BY TYPE OF FACILITY'}

\begin{tabular}{lcc|cc}
\cline { 2 - 5 } & \multicolumn{2}{c|}{ HIV Health } & \multicolumn{2}{c}{ Basic Health } \\
\cline { 2 - 5 } & $\begin{array}{c}\text { YFS } \\
(\mathrm{n}=\mathbf{3 0})\end{array}$ & $\begin{array}{c}\text { Non-YFS } \\
(\mathrm{n}=54)\end{array}$ & $\begin{array}{c}\text { YFS } \\
(\mathrm{n}=69)\end{array}$ & $\begin{array}{c}\text { Non-YFS } \\
(\mathrm{n}=\mathbf{2 4 3})\end{array}$ \\
\hline Free & 80.0 & 68.5 & 7.3 & 6.2 \\
$<10$ birr & - & - & - & 3.7 \\
10 birr & 3.3 & 1.9 & 1.5 & 1.2 \\
$>10$ birr & 16.7 & 27.8 & 88.4 & 86.4 \\
\hline
\end{tabular}

${ }^{+}$Column percentages do not add to $100 \%$ due to missing values.

TABLE 51. AFFORDABILITY OF SERVICES RECEIVED

\begin{tabular}{lcc:cc} 
& \multicolumn{2}{c}{ HIV Health } & \multicolumn{2}{c}{ Basic Health } \\
\cline { 2 - 5 } & $\begin{array}{c}\text { YFS } \\
(\mathrm{n}=7)\end{array}$ & $\begin{array}{c}\text { Non-YFS } \\
(\mathrm{n}=16)\end{array}$ & $\begin{array}{c}\text { YFS } \\
(\mathrm{n}=63)\end{array}$ & $\begin{array}{c}\text { Non-YFS } \\
(\mathrm{n}=\mathbf{2 3 1})\end{array}$ \\
\hline Affordable & 85.7 & 93.8 & 74.6 & 57.1 \\
Not affordable & 14.3 & 6.3 & 25.4 & 42.9 \\
Total & 100.0 & 100.0 & 100.0 & 100.0 \\
\hline
\end{tabular}




\section{Discussion}

The purpose of this quantitative study was to assess the SRH service knowledge, preferences, and utilization behaviors of youth aged 12-24 years across rural and peri-urban areas in five regions of Ethiopia. Youth in this study included females and males, married and unmarried, in school and out of school.

\section{Youth Autonomy}

In this study, youth autonomy was assessed both in terms of obtaining permission to leave the household and decision-making around certain aspects of life. The results suggest that many youth have limited decision-making power in relation to their health, school-related matters, and social groups. About 1 in $2(50 \%$ female, $46 \%$ male) youth reported that someone else makes the decision about their own health, while $42 \%$ of females and $35 \%$ of males reported that someone else decides who they can spend time with.

The results also indicate that youth need to inform someone in their household before they leave. Regardless of age, marital status, or school status, the overwhelming majority of female $(93 \%)$ and male $(85 \%)$ youth required permission to leave the house. Typically, permission is required from mothers or fathers for both males and females. Among married women, the majority (82\%) required permission from the husbands. Interestingly though, $37 \%$ of married men required permission to leave the house from their wives. It is not uncommon for youth under the age of 18 years who are living at home to inform someone in the household of their whereabouts before they leave the house. However, this can be a significant barrier to the use of contraceptive services, especially if the nearest service delivery outlet is roughly 30-60 minutes away by foot.

\section{Basic Health Service Preference}

Youth were asked which of 11 facility- and provider-based characteristics were important in the basic health services they use. The majority of respondents felt that all aspects of basic health services were important. The only factor that was not as important as others was that no one from the community would know of their visit. This is not surprising, as we would expect youth to feel less concern around being seen seeking basic health services, since those services are not associated with the stigmas that sexual and reproductive health services are.

\section{Basic Health Services and Youth Friendly Services}

While the majority of youth reported that basic health services could be obtained from a health center (91\% females, $88 \%$ males), less than half used basic health services in the past year (37\% females, 39\% males). This suggests that either the study population is a relatively healthy population, meaning that they do not require basic health services because they are not getting sick, or that barriers exist that prevent youth from accessing basic health services.

When asked, a small proportion of respondents had heard of youth friendly services ( $7 \%$ females, $8 \%$ males). While this proportion is small, youth interviewed may not recognize the name "youth friendly services" nor the difference in the way youth friendly services are offered compared to non-youth friendly services. Youth friendly services are not advertised as such, so therefore we did not expect there to be a high proportion of youth who recognized the term youth friendly services. Of those who knew about youth friendly services, the most common service known to be available was HIV counseling, testing, and treatment, among both females and males. The second most mentioned service known to be offered at youth friendly services was contraceptive services.

Only $2 \%$ of females and $4 \%$ of males reported ever using youth friendly services. But among those who did use services, a little less than half (45\%) of females and more than half $(57 \%)$ of males reported having used more than one service. It was not ascertained whether more than one service type was used in one visit to the YFS site or during multiple visits. 
Distance to a youth friendly service is an important factor in the utilization of these services. Among those who used youth friendly services, $84 \%$ of females and $60 \%$ of males lived within $5 \mathrm{~km}$ of a YFS facility, while $16 \%$ of females and $34 \%$ of males lived within 5 to $10 \mathrm{~km}$ of a YFS facility.

\section{Contraception}

We asked respondents about their provider preference, places where they could receive contraceptive services, and contraceptive knowledge and utilization. When asked about preferred location to receive contraceptive services or condoms, $62 \%$ of females and $49 \%$ of males reported health centers because health centers are located close to home, work, or school and offer low-cost or free services. The majority of females $(82 \%)$ and males $(71 \%)$ reported that they would prefer to see a physician, nurse, or midwife in a health facility. In addition, 1 in 4 respondents ( $22 \%$ females, $25 \%$ males) also reported that a health extension worker (HEW) who visits the home would be their preferred provider of contraceptives or condoms. In rural and peri-urban areas where health centers can be located far away, home-based contraceptive services would offer an alternative way of reaching youth.

While awareness of contraceptive methods was very high among this population (95\% of females and males knew of at least one modern method), current contraceptive use among sexually active females 1524 years old was $36 \%$. Among sexually active married females, $40 \%$ were using contraception compared to $30 \%$ of sexually active single females. Though 1 in 3 sexually active single females are using contraception, only $5 \%$ of all single females interviewed reported ever having sex.

Not surprisingly, the majority of contraceptive users in this study population are using reversible methodsinjectables (24\%), implants (8\%), and pills (3\%). Among those who are not currently using contraception, the majority $(81 \%)$ reported that they intend to use in the future and the methods of choice are the injectable (60\%), the pill (22\%), implants (14\%), and IUDs (3\%).

Male youth were asked about their knowledge and use of condoms: while knowledge was high, roughly $50 \%$ of sexually active males reported that they had ever used a condom. Among those who reported using condoms, $73 \%$ had used one at last sex. The primary reasons why males reported not using a condom at last sex was that they were in a stable relationship or wanted children.

\section{Use of Service at YFS Sites vs Non-YFS Sites}

Many youth are using health services at YFS sites without realizing it. For example, of the 187 female youth who reported using contraceptive services in the past 6 months, 33\% $(n=62)$ did not know whether they had gone to a youth friendly service site. This suggests that better promotion of the availability of youth friendly services at facilities may be necessary.

Most females and males who went to a facility for SRH services and basic health services in the 6 months preceding the survey traveled by foot to reach the facility. Among female youth who accessed FP, maternal health and basic health services, the mean travel time by foot was greater for those who went to YFS sites compared to non-YFS sites. Similarly, the average time for male youth to reach a YFS facility for HIV or basic services was greater than for males who went to non-YFS sites. These findings suggest that either the nearest facility for some youth was a long distance away, or that youth prefer using services from a specific facility that may be further away from their residence.

Overall quality of services received was high at both YFS and non-YFS sites. Both female and male respondents who went to a YFS site or a non-YFS site reported that they were treated well, felt comfortable asking questions and felt that the provider was knowledgeable. Waiting time to be seen, however, was slightly longer at YFS sites for female youth accessing family planning or basic health services and for male youth accessing basic health services. Youth friendly services are not advertised as such, so therefore we did not expect there to be a high proportion of youth who recognized the term youth friendly services. There are some indications from the results that YFS may be better in some aspects of quality. For example, youth who went to a non-YFS site were more likely to say the provider make them feel bad about themselves. 
These data demonstrate that quality of services offered at both YFS and non-YFS sites is high, and there is little to no difference in quality of services received by site type. There may be a number of reasons for this. One possibility is that trained YFS providers no longer provide services at the YFS site and moved to a non-YFS site. To test this hypothesis, monitoring data would be required to assess who participated in a training and their current location of employment. Respondent bias may also be contributing to these findings, leading respondents to respond to the questions favorably as opposed to their actual experiences.

\section{LIMITATIONS OF THE STUDY}

There were several limitations and challenges encountered during study implementation that should be considered when reviewing these results. The first limitation is that the YFS sites that were randomly selected from the list of functional YFS sites may be low-performing. That is, the study team did not purposively select sites that had a high client load. In the randomization, however, we would expect to have a variety of YFS sites ranging from high to low performance.

Another limitation of the study is that respondents were asked about their past behaviors, such as age of menarche, age at first sex, and use of health services. While recall bias may occur in these questions, recall is pretty good around major physical milestones among this age group. We also limited the health service utilization questions to a time period of 6 months to reduce recall bias.

To obtain a deeper understanding of the quantitative findings, the original study protocol had included qualitative interviews with an array of individuals that could not be completed. Interviews with users of YFS and non-YFS would have provided more information around service utilization experience, challenges, and recommendations from youths' perspectives. In addition, in-depth interviews with influencing adults, such as parents or adult guardians, would have provided more information on community perceptions of youths' access to and use of sexual and reproductive health services. Moreover, this study did not conduct interviews with YFS site administrators or providers, which would have provided some important insights into perceptions of YFS from the supply-side. Additional limitations are related to the respondents' knowledge and awareness. For example, respondents may have used YFS sites and peer educators but did not know them as such. This would underestimate the proportions of YFS knowledge and use. Politeness bias, especially as it relates to measures of service quality, may also be captured in these results. This type of bias would result in higher levels of reported quality than actually received. Related to this, young people's lack of experience accessing services may also have led to an overestimation of quality.

Finally, respondents of this age may have been more or less likely to provide honest responses to some of the more sensitive topics such as sexual intercourse and contraceptive use because of the face-to-face interviews. The study team tried to increase honest responses by hiring females and males to conduct samesex interviews who also had previous experience working with youth. All interviews were conducted with privacy to assure respondents that their responses were private and confidential.

\section{STUDY IMPLICATIONS}

This study was designed to understand youths' perspectives and use of sexual and reproductive health services, specifically among those living in rural and peri-urban areas. Barriers to use of basic health services and youth friendly services that were identified included limited mobility and decision-making around their own health, perceptions of unmarried youths' use of contraception, and distance to the nearest health facility.

Findings showed that youth are mostly sexually active in the context of marriage. Very few single female youth were sexually active. This suggests that the SRH client who would most likely use youth friendly services is married, and yet in the context of Ethiopia, once youth are married, they are not considered youth. Programs need to find ways of reaching young married youth with SRH services.

This study also showed that youth (including boys) have limited mobility and decision-making around their own health. While parental supervision and involvement is important among younger youth (i.e. 
12-14 year olds), lack of mobility and decision-making may limit the ability of sexually active youth, who by and large are married, to access SRH services, especially when SRH services are considered taboo or unnecessary. Future research is needed to understand community members' (parents, guardians, in-laws, teachers, religious leaders, etc.) perspective of married youths' use of SRH services and notions of sex by unmarried youth. Research in this area could aid in the design of programs that reduce negative attitudes of gatekeepers who can prevent married and unmarried youths' use of SRH services.

The study found that youth viewed use of contraception by unmarried youth as a sign of promiscuity. Programs that focus on developing youth agency and empowerment around SRH services could temper these attitudes. Furthermore, attitudes of youth are generally formed by the communities they live in and individuals they interact with, which can include individuals in their household, their peer groups, their schools, or the community at large. Programs need to engage with an array of individuals in the community to begin addressing the stigma associated with youth access to SRH services.

Previous research has shown that distance is a factor in youth access to SRH services and this study confirms this finding. One in four female youth surveyed reported that the nearest health facility offering basic health services was over an hour away. Similarly, 1 in 4 female youth who had recently used contraceptive services reported they traveled over 1 hour by foot to reach the health facility. While the placement of a health facility may be difficult to change, programs that aim at bringing health services to youth where they live could be explored. For example, programs may consider training health extension workers (HEWs) who already offer antenatal care, HIV testing, and family planning among other services, to provide SRH services to youth in their households. This is especially important for young married individuals who have limited mobility, but with the proper outreach to gatekeepers/in-laws may be able to access SRH information and services from HEWs in their households.

Youth who used youth friendly services for contraception were generally unaware that they accessed YFS. This raises the question of whether programs should try to increase the visibility/name recognition of youth friendly services, but is this a financially sound approach? The results also demonstrate high levels of satisfaction with contraceptive services and quality of services received at both YFS sites and nonYFS sites. This suggests that programmers and policymakers need to consider how their resources and investments should be made moving forward.

The results of this study demonstrate that there needs to be a paradigm shift in how services are being offered to youth in Ethiopia. A more holistic approach needs to be taken to meet the SRH needs of youth in Ethiopia beyond the development of youth friendly service sites. Programs need to bring services to youth in their communities and homes while generating demand for these services and changing community norms around youth SRH services. Programs also need to target young married youth, because they are predominantly the ones utilizing youth friendly services for SRH services. 


\section{References}

Abajobir, A.A., \& Seme, A. (2014). Reproductive health knowledge and services utilization among rural adolescents in east Gojjam zone, Ethiopia: a community-based cross-sectional study. BMC Health Services Research, 14, 138. doi:10.1186/1472-6963-14-138

Berhane, F., Berhane, Y., \& Fantahun, M. (2005). Adolescents' health service utilization pattern and preferences: Consultation for reproductive health problems and mental stress are less likely. Ethiopian Journal of Health Development, 19(11), 29-37.

Brittain, A.W., et al. (2015). Youth-friendly family planning services for young people: a systematic review. American Journal of Preventive Medicine, 49(2), S73-S84.

Central Statistical Agency [Ethiopia] and ICF International. 2012. Ethiopia Demographic and Health Survey 2011. Addis Ababa, Ethiopia and Calverton, Maryland, USA: Central Statistical Agency and ICF International.

Central Statistical Agency (CSA) [Ethiopia] and ICF. 2016. Ethiopia Demographic and Health Survey 2016: Key Indicators Report. Addis Ababa, Ethiopia, and Rockville, Maryland, USA. CSA and ICF.

Chandra-Mouli, V., et al. (2015). Twenty years after International Conference on Population and Development: where are we with adolescent sexual and reproductive health and rights? Journal of Adolescent Health, 56(1), S1-S6.

Cherie, A., \& Berhane, Y. (2012). Knowledge of sexually transmitted infections and barriers to seeking health services among high school adolescents in Addis Ababa, Ethiopia. Journal of AIDS and Clinical Research, 3(5), 1-6.

Erulkar, A.S., et al. (2010). Ethiopia young adult survey: a study in seven regions. New York, USA: Population Council.

Erulkar, A. S., et al. (2006). Differential use of adolescent reproductive health programs in Addis Ababa, Ethiopia. Journal of Adolescent Health, 38(3), 253-260. doi:10.1016/j.jadohealth.2005.03.026

Feleke, S. A., et al. (2013). Reproductive health service utilization and associated factors among adolescents (15-19 years old) in Gondar town, Northwest Ethiopia. BMC Health Services Research, 13(1), 294.

Hainsworth, G., et al. (2014). Scale-up of adolescent contraceptive services: lessons from a 5-country comparative analysis. Journal of Acquired Immune Deficiency Syndrome, 66 Suppl 2, S200-208. doi:10.1097/qai.0000000000000180

High-Impact Practices in Family Planning (HIPs). (2015). Adolescent-friendly contraceptive services: mainstreaming adolescent-friendly elements into existing contraceptive services. Washington (DC): USAID. Available from: https://www.fphighimpactpractices.org/afcs

Pathfinder. (2012). Bringing Youth-Friendly Services to Scale in Ethiopia.

Seifu, A., Fantahun, M., \& Worki, A. (2006). Reproductive health needs of out-of-school adolescents: A cross-sectional comparative study of rural and urban areas in northwest Ethiopia. Ethiopian Journal of Health Development, 20(1), 10-17. 


\section{Appendix}

\section{BOX 1}

\section{CHARACTERISTICS OF YOUTH FRIENDLY SERVICES}

Adolescent friendly procedures to facilitate:

- Easy and confidential registration of patients, retrieval and storage of records, short waiting times, and (where necessary) swift referral

- Consultation with or without an appointment

Adolescent friendly health care providers who:

- Are technically competent in adolescent-specific areas and offer health promotion, prevention, treatment, and care relevant to each client's maturation and social circumstances

- Have interpersonal and communication skills, are motivated and supported, are nonjudgmental and considerate, easy to relate to, and trustworthy

- Devote adequate time to clients or patients, act in the best interests of their clients, treat all clients with equal care and respect

- Provide information and support to enable each adolescent to make the right free choices for his or her unique needs

Adolescent friendly support staff who are:

- Understanding and considerate, treating each adolescent client with equal care and respect

- Competent, motivated, and well supported

Adolescent friendly health facilities that:

- Provide a safe environment at a convenient location with an appealing ambiance

- Have convenient working hours

- Offer privacy and avoid stigma

- Provide information and educational material

Adolescent involvement, so that they are:

- Well informed about services and their rights

- Encouraged to respect the rights of others

- Involved in service assessment and provision

Community involvement and dialogue to:

- Promote the value of health services

- Encourage parental and community support

Community-based outreach and peer-to-peer:

- Services to increase coverage and accessibility

- Appropriate and comprehensive services that address each adolescent's physical, social, and psychological health and development need

- Provide a comprehensive package of health care and referral to other relevant services

- Do not carry out unnecessary procedures

Effective health services for adolescents:

- That are guided by evidence-based protocols and guidelines

- Having equipment, supplies, and basic services necessary to deliver the essential care package

- Having a process of quality improvement to create and maintain a culture of staff support.

Efficient services that have:

- A management-information system including information on the cost of resources

- A system to make use of this information 
The Evidence Project

Population Council

4301 Connecticut Avenue, NW, Suite 280

Washington, DC 20008 USA

tel +1 2022379400

evidenceproject.popcouncil.org 